\title{
POLLUTION PREVENTION PROGRAM PLAN
}

1996

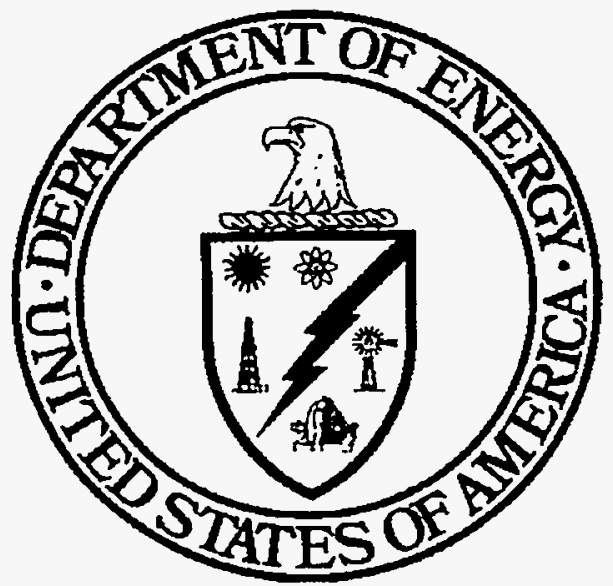

U.S. DEPARTMENT OF ENERGY OFFICE OF THE SECRETARY 
This report has been reproduced directly from the best available copy.

Available to DOE and DOE Contractors from the Office of Scientific and Technical Information, P.O. Box 62, Oak Ridge, TN 37831; prices available from (615) 576-8401.

Available to the public from the U.S. Department of Commerce, Technology Administration, National Technical Information Service, Springfield, VA 22161, (703) $487-4650$. 


\section{POLLUTION PREVENTION PROGRAM PLAN}

1996

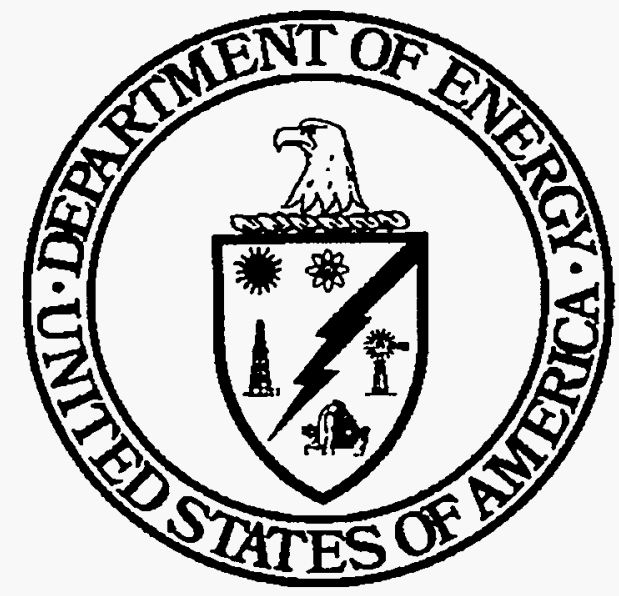

U.S. DEPARTMENT OF ENERGY

OFFICE OF THE SECRETARY

WASHINGTON, DC 20585 
$\because \cdots \cdots$

$\because$ 


\section{The Secretary of Energy \\ Washington, DC 20585}

May 3, 1996

\section{MEMORANDUM FOR HEADS OF DEPARTMENTAL ELEMENTS \\ FROM: \\ HAZEL R. O'LEARY}

SUBJECT: Departmental Pollution Prevention Goals

The Department of Energy pollution prevention strategy is to reduce the generation of all waste streams and thus minimize the impact of departmental operations on the environment. Preventing pollution also reduces risks to the health and safety of workers and the general public and saves scarce budget dollars. To demonstrate the Department's commitment to pollution prevention, we have set the following goals to be achieved by December 31, 1999, using calendar year 1993 as a baseline year.

\section{For Routine Operations:}

- Reduce by 50 percent the generation of radioactive waste.

- Reduce by 50 percent the generation of low-level mixed waste.

- Reduce by 50 percent the generation of hazardous waste.

- Reduce by 33 percent the generation of sanitary waste.

- Reduce by 50 percent total releases and off-site transfers for treatment and disposal of toxic chemicals.

For All Operations, Including Cleanup/Stabilization Activities:

- Recycle 33 percent of sanitary waste.

For Affirmative Procurement:

- Increase procurement of Environmental Protection Agency-designated, recycled products to 100 percent, except where they are not commercially available competitively at a reasonable price or do not meet performance standards.

Operations Offices will direct sites under their purview to set site-specific goals to assist in achieving the departmental goals. Progress toward meeting the departmental goals will be reported annually to me. It is the responsibility of each Federal and contractor manager to work diligently to meet these goals; to aggressively seek ways to reduce the amount of pollutants generated within the workplace; and to conserve, reuse, and recycle resources. 


Po




\section{EXECUTIVE SUMMARY}

This plan serves as the principal crosscutting guidance to Department of Energy (DOE) Headquarters, Operations Office, laboratory, and contractor management to fully implement pollution prevention programs within the DOE complex between now and 2000 .

To firmly demonstrate DOE's commitment to pollution prevention, the Secretary of Energy has established goals, to be achieved by December 31, 1999 , that will aggressively reduce DOE's routine generation of radioactive, mixed, and hazardous wastes, and total releases and offsite transfers of toxic chemicals (see Section 1.2). The Secretary also has established sanitary waste reduction, recycling, and affirmative procurement goals. Site progress in meeting these goals will be reported annually to the Secretary in the Annual Report on Waste Generation and Waste Minimization Progress, using 1993 as the baseline year.

This plan encourages Federal and contractor managers to undertake the following actions, beginning in fiscal year 1996, to achieve the Secretary's pollution prevention goals:

- Each individual site shall develop its own goals, designed to help achieve the DOE-wide goals, and should submit those goals and appropriate Activity Data Sheets (ADSs) to its Operations Office for review.

- Operations Office managers should prioritize pollution prevention ADSs submitted by the sites, and work with their Headquarters Cognizant Secretarial Office (CSO) counterparts to ensure that budgets are formulated to achieve the Secretarial goals.
- Each Operations Office should direct its reporting sites to plan for and implement the priorities identified in this plan, and should take necessary measures to ensure their successful completion within allocated budgets.

- Headquarters CSOs that generate waste should allocate funds by approving.site-specific goals and ADSs to reduce pollutants and long-term waste costs (e.g., by funding return-on-investment projects). In addition, each wastegenerating CSO should identify an annual pollution prevention budget associated with site resource requirements, and should exercise diligence to budget for, and achieve, the goals set forth in this plan.

- Each Operations Office and site should make every effort to implement all applicable elements of the Secretary's December 28, 1994, Pollution Prevention Strategy (see Appendix B).

Implementation of this plan will represent a major step toward reducing the environmental risks and costs associated with DOE operations. Accordingly, CSOs and Operations Office managers should carry out the following six pollution prevention priorities immediately:

- establish senior management commitment to pollution prevention implementation;

- $\quad$ set quantitative, site-specific source reduction and recycling goals;

- institute performance measures;

- implement cost-saving pollution prevention projects;

- design pollution prevention into new products, processes, and facilities; and 
- ensure that site programs comply with Federal, State, and Departmental requirements.

Operations Offices may take into consideration that resources are limited at DOE's small sites, and implement only those portions of the Pollution Prevention Activity Plan (see Appendix D) appropriate to the size and scope of such sites (see Table 3.1). This will help ensure that there is value added to the activities implemented compared to the costs incurred. 


\section{FOREWORD}

\section{DEPARTMENT OF ENERGY MISSION}

The Department of Energy, in partnership with its customers, is entrusted to contribute to the welfare of the Nation by providing the technical information and the scientific and educational foundation for the technology necessary to achieve efficiency in energy use, diversity in energy sources, a more productive and competitive economy, improved environmental quality, and a secure national defense.

\section{CORE VALUE - RESPECT THE ENVIRONMENT}

- We will be a leader in improving the quality of the environment for future generations.

- We recognize the importance of the environmental impacts of our operations, and we develop and employ processes and technologies to reduce or eliminate waste production and pollution in these operations.

- We place a high priority on the protection of public health and safety and restoration of the environment through cleanup of environmental damage caused by past operations.

\section{POLLUTION PREVENTION MISSION}

The Department's pollution prevention mission is to minimize the generation and release of pollutants to the environment by implementing cost-effective pollution prevention technologies, practices, and policies with partners in government and industry. The Department will simultaneously conduct its operations in such a way as to minimize impact on the environment, improve the safety of operations and energy efficiency, and promote the sustainable use of natural resources. 
Pollution Prevention Program Plan 


\section{Confents}

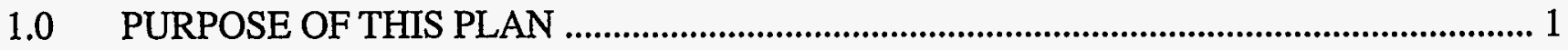

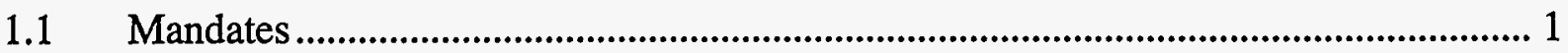

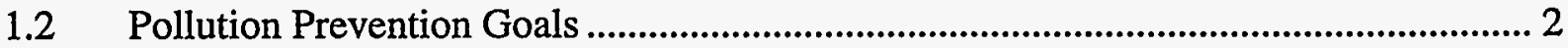

1.3 DOE Pollution Prevention Priorities ..................................................................... 4

1.4 Vision of the Future - Year 2000 ....................................................................... 4

1.5 External Pollution Prevention Programs ....................................................... 4

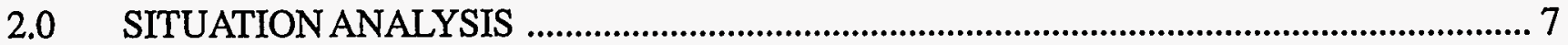

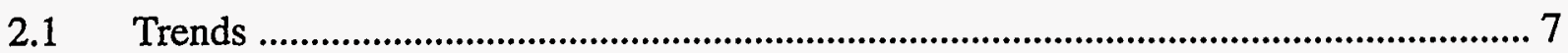

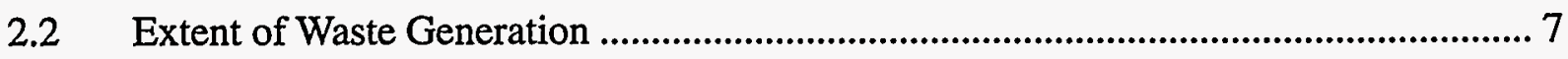

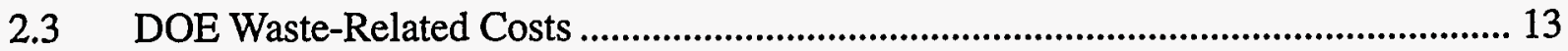

2.4 Pollution Prevention Investments by Sites and CSOs ............................................ 13

2.5 Strengths of the Overall DOE Pollution Prevention Program ................................. 14

2.6 Challenges to Implementing a Complete Program ................................................... 15

2.7 Opportunities for Pollution Prevention..................................................................... 16

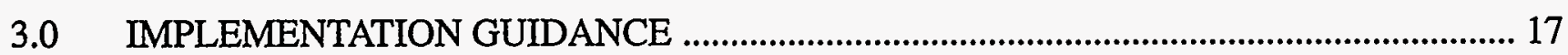

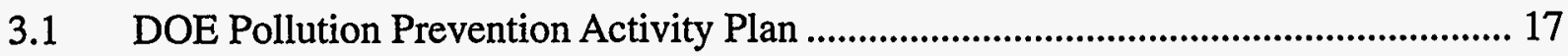

3.2 Activity Plan Implementation Strategy .......................................................... 17

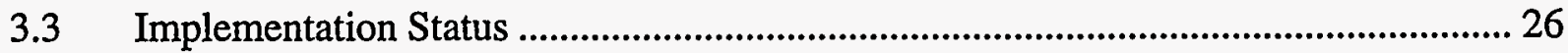

Site Pollution Prevention Plans ........................................................................ 28

3.5 Guidance on Funding Pollution Prevention ......................................................... 28

3.6 Pollution Prevention Roles and Responsibilities ................................................ 29

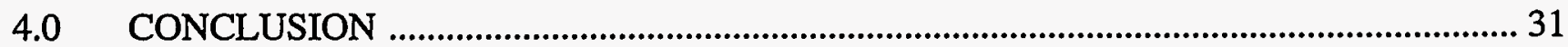




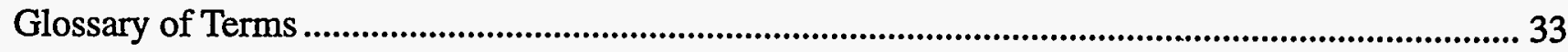

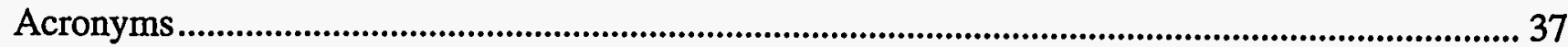

Appendix A: DEFINITION OF POLLUTION PREVENTION ................................................. A-1

Appendix B: U.S. DOE POLLUTION PREVENTION STRATEGY ......................................... B-1

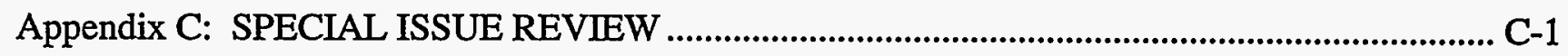

Appendix D: POLLUTION PREVENTION ACTIVITY PLAN ............................................... D-1

Appendix E: ROLES AND RESPONSIBLITIES ............................................................ E-1 


\section{Figures}

Figure 2.1 1993 Percentages of Routine Operations and Cleanup/Stabilization

Waste Generation for Hazardous and Radioactive Waste Types .................................. 9

Figure 2.2 1993 DOE Facility Releases and Transfers for Treatment and Disposal by TRI Chemical

Figure 2.3 CY 1993 DOE Facility Releases and Transfers of TRI Chemicals for Treatment and Disposal by Site

Figure 2.4 Projected Total Waste Volumes by Waste Type and Generation Category

During the Lifetime of the Cleanup Effort

Figure 2.5 Projected Cost Estimates for the Life of the Environmental

Management Program........................................................................................... 14

Figure 3.1 Work Breakdown Structure of DOE's Pollution Prevention Program ....................... 18

Figure 3.2 Cumulative Cost Savings to the Department from Achievement of Secretarial Waste Reduction Goals ....................................................................................... 21

Figure 3.3 Pollution Prevention Case Study ......................................................................... 24

Figure 3.4 Status and Priority of DOE Implementation of Pollution Prevention Activities ........ 27

Figure D.3.1 Key Elements of a Compliant Site Pollution Prevention Program ......................... D-5

Figure D.3.2 Key Elements of a Generator Specific Pollution Prevention Program ..................... D-6 


\section{Tables}

Table 1.1 Comparison of DOE and Other Agency Waste Reduction and Recycling Goals ..................................................................................................... 3

Table 2.1 Summary of Waste Generation Rates for 1991 through 1993 by Cognizant Secretarial Office ............................................................................................................... 8

Table 2.2 Department-Wide Generation Rates for 1991 through 1993 by Waste Type ................ 9

Table 2.3 Draft 1996 BEMR Projected Waste Volumes During the Lifetime of the Cleanup Effort 12

Table 2.4 Total DOE Dedicated Pollution Prevention Budgets for FY 95 \& 96 ......................... 15

Table $3.1 \quad$ Small Site Implementation Criteria ........................................................................ 17

Table 3.2 Departmental Source Reduction and Recycling Goals, Compared to the 1993 Baseline of Waste Generation ............................................................................... 19

Table 3.3 Projected Annual Cost Savings to be Realized by Achieving Secretarial Goals ........ 20

Table 3.4 Pollution Prevention Performance Measures, Routine Waste Only ............................. 22

Table 3.5 Pollution Prevention Performance Measures, All Operations ....................................... 22

Table 3.6 Summary of DOE Roles and Responsibilities for Implementing Pollution Prevention 


\subsection{PURPOSE OF THIS PLAN}

This document is the Secretary of Energy's plan for U.S. Department of Energy (DOE) Headquarters, Operations Offices, laboratories, and contractor organizations regarding specific steps they should take to meet DOE's pollution prevention commitments. It is the third in a series of pollution prevention documents issued by the Office of the Secretary over the past 4 years. This plan builds upon the Waste Minimization Crosscut Plan (DOE/S-0094P), issued in 1992, and the Waste Minimization/Pollution Prevention Crosscut Plan (DOE/FM-0145), issued in 1994. This plan:

- discusses goals and goal-setting criteria to reduce waste generation, reduce the use and release of toxic chemicals, and increase recycling and affirmative procurement of recycled products;

- identifies priorities in accomplishing the Department's implementation strategy; and

- describes, via an Activity Plan, the steps necessary to establish a comprehensive pollution prevention program.

The Department's focus to date has primarily been on source reduction and recycling of sanitary wastes to reduce the amount of waste requiring treatment, storage, and disposal. This plan expands the scope to include other waste types; releases of pollutants to air, soil, and water; energy efficiency; and resource conservation.

The Department's goal is to maintain a consistent and comprehensive program throughout the complex to take full advantage of the benefits of pollution prevention. This plan presents DOE's pollution prevention policy, strategy, and direction. It also serves as the primary mechanism for priori- tizing pollution prevention activities and accelerating implementation. The plan will be updated as necessary to reflect the latest pollution prevention goals, directives, strategies, and progress. The Department's definition of pollution prevention is found in Appendix A.

\subsection{Mandafes}

While there are many Federal requirements for implementing pollution prevention within the Department (several of which will be discussed later in this section), it is important to recognize that the primary reason for pollution prevention is good business practice. Each Federal and contractor employee within the Department is expected to make the best use of resources to achieve the most favorable outcome in any given activity. Pollution prevention can help employees do just that because it promotes efficiency, saves money, and creates a sense of shared responsibility at each site. When pollution prevention becomes the ethic of every employee at a site, meeting the requirements discussed in the following paragraphs need not be difficult.

DOE Order 5400.1, "General Environmental Protection Program," requires Heads of Field Organizations to prepare plans for their pollution prevention awareness program activities. Such plans shall be reviewed annually and updated every 3 years. Plans were last submitted to Headquarters in 1994.

The United States Congress, through the enactment of the Pollution Prevention Act of 1990, has established pollution prevention as the preferred approach to managing environmental releases. The act establishes source reduction as the national strategy of first choice to reduce the generation of pollution. 
To emphasize the importance of pollution prevention, President Clinton issued Executive Order 12856, "Federal Compliance With Right-to-Know Laws and Pollution Prevention Requirements," on August 3, 1993. The Executive Order encourages pollution prevention leadership within the Federal government. It directs that all Federal agencies develop goals to reduce by 50 percent their total releases to the environment and off-site transfers for treatment and disposal of toxic chemicals regulated under the Emergency Planning and Community Right-to-Know Act (EPCRA), section 313, by December 31, 1999. In addition, each Federal agency must review its specifications and standards and identify opportunities to eliminate or reduce the use of toxic chemicals. Further, each agency, and each facility within that agency required to comply with EPCRA Section 313 , must have a plan with goals to eliminate or reduce the unnecessary acquisition of products containing toxic chemicals.

Executive Order 12969, "Federal Acquisition and Community Right-to-Know," signed by the President on August 8, 1995, states that "Federal agencies, to the greatest extent practicable, shall contract with companies that report in a public manner on toxic chemicals released to the environment." This statement applies to Federal contracts that are expected to equal or exceed $\$ 100,000$. The Order also states that Federal agencies may amend existing contracts, to the extent permitted by law and where practicable, to require reporting.

Executive Order 12873, "Federal Acquisition, Recycling, and Waste Prevention" (October 1993), directs the appointment of Federal agency environmental executives to develop and implement acquisition programs aimed at encouraging new technologies and building markets for environmentally preferable and recycled products. Federal agencies also must set goals for waste reduction, recycling, and the acquisition of recycled products, and report on their progress in meeting the goals.

In addition, this Executive Order requires that Federal agencies purchase 100 percent of those recycled items designated by the Environtal Protection Agency (EPA), except where the items are not available competitively at a reasonable price within a reasonable time frame, or if they do not meet appropriate performance standards. Purchasing non-recycled versions of the EPA-designated items will require written justification citíng one or more of the above conditions.

Executive Order 12902, "Energy Efficiency and Water Conservation at Federal Facilities" (March 1994), directs Federal agencies to develop and implement programs, to the extent they are cost effective, aimed at: 1) reducing overall energy use in Federal buildings 30 percent by $2005 ; 2$ ) increasing overall energy efficiency in industrial Federal facilities 20 percent by $2005 ; 3$ ) significantly increasing the use of solar and other renewable energy sources; and 4) minimizing the use of petroleum products at Federal facilities by switching to less polluting energy sources.

As required by Executive Order 12856, the Secretary of Energy, on December 28, 1994, issued DOE's Pollution Prevention Strategy, to be implemented by all Departmental elements (Appendix B). This document establishes pollution prevention as DOE's primary strategy to reduce the generation of all waste streams and thereby minimize the impact of Departmental operations on the environment, reduce operational costs, and improve energy efficiency and safety. 


\subsection{Pollution Prevention Gouls}

The Secretary of Energy has committed the Department to the following pollution prevention goals, to be achieved complex-wide by December 31, 1999 , using calendar year (CY) 1993 as a baseline:

- Reduce total releases and offsite transfers for treatment and disposal of EPCRA 313 toxic chemicals from routine operations 50 percent.

- Reduce the generation of radioactive waste from routine operations 50 percent.

- Reduce the generation of low-level mixed waste from routine operations 50 percent.

- Reduce the generation of hazardous waste from routine operations 50 percent.

- Reduce the generation of sanitary waste (after recycling) from routine operations 33 percent.
- Divert for recycling 33 percent of sanitary waste from all operations.

- Increase the affirmative procurement of EPAdesignated recycled products to 100 percent.

By setting these goals, the Department joins other agency leaders in pollution prevention, as shown in Table 1.1. Progress toward achieving the goals will be reported annually to the Secretary in the Annual Report on Waste Generation and Waste Minimization Progress. These goals are discussed in greater detail in Section 3.2.2.

Individual sites are encouraged to develop their own goals that meet or exceed the above complexwide goals, against which DOE must report. Effective goal-setting and follow-through is the cornerstone of management commitment. It is the responsibility of Headquarters Cognizant Secretarial Offices (CSOs), Operations Office managers,

Table 1.1 Comparison of DOE and Other Agency Waste Reduction and Recycling Goals by Calendar Year

\begin{tabular}{|l|c|c|c|c|c|c|}
\hline \multicolumn{2}{|c|}{ Goal } & \multicolumn{2}{|l|}{ Department of Energy } & \multicolumn{2}{|c|}{$\begin{array}{c}\text { Department of Defense } \\
\text { (All Service Branches) }\end{array}$} & \multicolumn{2}{l|}{ U.S. Postal Service } \\
\cline { 2 - 8 } & $\begin{array}{c}\text { Baseline } \\
\text { Year }\end{array}$ & $\begin{array}{c}\text { By End of } \\
1999\end{array}$ & $\begin{array}{c}\text { Baseline } \\
\text { Year }\end{array}$ & $\begin{array}{c}\text { By End of } \\
1999\end{array}$ & $\begin{array}{c}\text { Baseline } \\
\text { Year }\end{array}$ & $\begin{array}{c}\text { By End of } \\
1999\end{array}$ \\
\hline $\begin{array}{l}\text { Toxic Chemical Release } \\
\text { Inventory Reduction }\end{array}$ & 1993 & $50 \%(1)$ & 1994 & $50 \%$ & 1994 & $\begin{array}{c}50 \% \\
(1995)\end{array}$ \\
\hline Hazardous Reduction & 1993 & $50 \%(1)$ & 1992 & $50 \%$ & 1992 & $\begin{array}{c}50 \% \\
(1995)\end{array}$ \\
\hline Radioactive Reduction & 1993 & $50 \%(1)(3)$ & NA & NA & NA & NA \\
\hline $\begin{array}{l}\text { Low-Level Mixed Waste } \\
\text { Reduction }\end{array}$ & 1993 & $50 \%(1)$ & NA & NA & NA & NA \\
\hline Sanitary Waste Reduction & 1993 & $33 \%(1)$ & 1992 & $50 \%$ & 1992 & $95 \%$ \\
\hline Recycling & NA(2) & $33 \%$ & NA(2) & $50 \%$ & NA(2) & $70 \%$ \\
\hline
\end{tabular}

(1) Environmental cleanup/stabilization wastes excluded; routine wastes only.

(2) Recycling baselines are established annually.

(3) Low-level wastes only. 
and heads of contractor organizations to ensure that appropriate goals are set and met.

\subsection{DOE Pollution Prevention Priorities}

This plan establishes six immediate Department-wide priorities, to be implemented by fiscal year (FY) 1998, that will help Headquarters, the Operations Offices, and the sites to focus resources on the most critical aspects of DOE's pollution prevention program. Longer term priorities are discussed in Section 3.3.

The six priorities are to:

- Establish senior management commitment to pollution prevention implementation.

- Set quantitative, site-specific waste reduction and recycling goals.

- Institute performance measures.

- Implement cost-saving pollution prevention projects.

- Design pollution prevention into new products, processes, and facilities.

- Ensure that site programs comply with Federal, State, and Departmental requirements.

Each of the six immediate priorities is described in more detail in Section 3.2.

\subsection{Vision of the Future - Year 2000}

DOE has a sustained, integrated commitment to pollution prevention at all levels. Acknowledged by its stakeholders as a responsible pollution prevention role model, the Department is recognized as a leader in:
- preventing pollution and conserving energy and other resources;

- incorporating pollution prevention into planning, operations, and design activities;

- reducing the cost of program operations and environmental compliance through source reduction and recycling;

- developing and using innovative technologies to prevent pollution and minimize releases from all DOE activities;

- encouraging pollution prevention through policies, procedures, and incentives;

- participating in the formulation of sound and effective environmental laws and regulations; and

- proactively involving stakeholders and the public in the planning and implementation of pollution prevention activities.

\subsection{External Pollution Prevention Programs}

This plan focuses on pollution prevention within DOE facilities and operations. However, many organizations within DOE provide critical support to industry, academia, and other Federal agencies to promote pollution prevention.

Work with external partners is beneficial to DOE's internal pollution prevention programs. Technologies developed with industry and other Federal agencies are applied to DOE operations and facilities. External partnerships also promote information exchange within and outside of the Department.

The Office of Energy Efficiency and Renewable Energy (EE) has the lead responsibility in helping industry become more competitive by cost-effectively 
shifting from waste management to pollution prevention and resource efficiency. Industrial pollution prevention is important to DOE because of the connection between energy use and waste generation. DOE's laboratories and facilities have expertise in areas that are critical to promoting industrial pollution prevention. DOE's core competencies include energy and environmental technologies, advanced materials development, high-performance computing and communications, and advanced manufacturing. For more information on the Department's external pollution prevention programs, contact the EE Office of Industrial Technologies' Technology Access Group at 202-586-0139. Information is also available on the Internet at $h t t p: / / w w w . e v e n . d o e . g o v / i n d u s t r y$. 


\subsection{SITUATION ANALYSIS}

This section provides an analysis of the current DOE pollution prevention program as it relates to its environmental management challenges. The extent of waste generation throughout the complex is described in order to identify areas to which pollution prevention can be applied. Programmatic strengths and weaknesses in implementing the pollution prevention program are discussed to demonstrate the progress DOE has made, and that which remains to be accomplished.

\subsection{Trends}

The Department, the President, and the Congress are working to bring the Federal budget into balance within the next several years. This and other developments led to the Department's Strategic Alignment Implementation Plan, issued by the Secretary on August 3, 1995. Over the next 5 years, the alignment will decentralize many Departmental functions by shifting responsibility for them to the field. The Department plans to cut $\$ 14.1$ billion from its budget over 5 years through productivity increases and a more tightly focused mission.

The Department continues to adjust to the end of the Cold War. Whereas the mission of DOE and its predecessor agencies over the past several decades had been nuclear weapons production, its current mission has largely shifted to weapons stewardship, energy research and development, and cleaning up from past practices. With facilities and sites being decommissioned, waste generation is increasing; much of the resulting waste must undergo costly treatment, storage, and disposal.

Cost-effective management, including treatment, storage, and disposal of environmental restoration wastes represents a significant Departmental challenge. Pollution prevention practices are at an early stage within environmental restoration activities and could contribute significantly to the success of these programs.

\subsection{Extent of Waste Generation}

Waste generation data contained in this plan originated from three sources: the DOE Annual Report on Waste Generation and Waste Minimization Progress, 1993 (Annual Report); the National Library of Medicine's TOXNET database; and the draft 1996 Baseline Environmental Management Report.

\subsubsection{Annual Report Findings}

The Annual Report contains waste generation data for calendar years 1991, 1992, and 1993. Beginning in 1993, the data were subdivided into routine operations wastes and cleanup/stabilization wastes for comparison purposes.

Routine Operations Waste - Normal operations waste produced from any type of production, analytical, and/or research and development laboratory operations; treatment, storage, or disposal operations; "work-for-others;" or any periodic and recurring work that is considered ongoing. The term "normal operations" refers to the type of ongoing process (e.g., production), not to the specific activity that produced the waste.

Cleanup/Stabilization Waste - Cleanup/stabilization encompasses a complex range of activities including environmental restoration of contaminated media (soil, groundwater, surface water, sediments, etc.); stabilization of nuclear and nonnuclear (chemical) materials; and deactivation and decommissioning (including decontamination) of facilities. Cleanup/stabilization waste consists of one-time operations waste produced from environmental restoration program activities, including primary and secondary wastes associated with retrieval and remediation operations; "legacy 
wastes;" and wastes from decontamination and decommissioning/transition operations. It also includes all Toxic Substances Control Act (TSCA) regulated wastes, such as polychlorinated biphenylcontaminated fluids and/or equipment. Note that cleanup/stabilization activities that generate wastes do not necessarily occur at a single point in time, but may have a duration of several years during which wastes are produced. By definition, these activities are not considered to be routine (periodic and/or on-going), because the waste is a direct result of past operations and activities, rather than of a current process. Newly generated wastes produced during these "one-time operations" are considered to be a secondary waste stream, and are separately accounted for whenever possible. This secondary (newly generated) waste usually results from common activities such as handling, sampling, treatment, repackaging, shipping, etc.
Periodic laboratory or facility clean-outs and spill cleanups which occur as a result of these processes are also considered normal operations.

Table 2.1 contains waste generation data for each CSO for calendar years 1991, 1992, and 1993. Table 2.2 shows DOE-wide waste generation rates by radioactive waste type (high-level, low-level, low-level mixed, and transuranic), and by hazardous and sanitary wastes.

In 1993, the Department demonstrated substantial progress in reducing low-level mixéd wastes. Despite a changing mission, however, the Department still generates more radioactive waste than it does sanitary waste. Much of this is due to DOE's environmental restoration activities, which retrieve previously generated radioactive waste, and its stabilization/deactivation and decommissioning activities, which retrieve primary wastes and generate secondary wastes as a function of cleaning facilities and sites.

Table 2.1 Summary of Waste Generation Rates for 1991 through 1993 by Cognizant Secretarial Office* (Source: Annual Report on Waste Generation and Waste Minimization Progress)

\begin{tabular}{|c|c|c|c|c|c|c|c|c|c|c|}
\hline \multirow{3}{*}{$\begin{array}{c}\text { Cognizant } \\
\text { Secretarial Office }\end{array}$} & \multicolumn{5}{|c|}{ Radioactive Waste $\left(\mathrm{m}^{\mathbf{3}}\right)^{\star *}$} & \multicolumn{5}{|c|}{ Hazardous Waste } \\
\hline & \multirow[b]{2}{*}{ CY 1991} & \multirow[b]{2}{*}{ CY 1992} & \multicolumn{3}{|c|}{ CY 1993} & \multirow[b]{2}{*}{ CY 1991} & \multirow{2}{*}{ CY 1992} & \multicolumn{3}{|c|}{ CY 1993} \\
\hline & & & $\begin{array}{c}\text { Routine } \\
\text { Operations }\end{array}$ & $\begin{array}{c}\text { Cleanup/ } \\
\text { Stabilization }\end{array}$ & Total & & & $\begin{array}{c}\text { Routine } \\
\text { Operations }\end{array}$ & \begin{tabular}{|c|} 
Cleanup/ \\
Stabilization
\end{tabular} & Total \\
\hline $\begin{array}{l}\text { Defense Programs } \\
\text { (DP) }\end{array}$ & 31,700 & 21,900 & 16,800 & 1,700 & 18,500 & 9,800 & 8,500 & 3,000 & 750 & 3,750 \\
\hline $\begin{array}{l}\text { Environmental } \\
\text { Management (EM) }\end{array}$ & 95,100 & 109,000 & 19,800 & 92,100 & 111,900 & 3,900 & 3,100 & 1,300 & $\cdot 27,500$ & 28,800 \\
\hline $\begin{array}{l}\text { Energy Research } \\
\text { (ER) }\end{array}$ & 5,200 & 5,000 & 2,100 & 200 & 2,300 & 1,800 & 1,400 & 2,000 & 1,800 & 3,800 \\
\hline Nuclear Energy* (NE) & 6,000 & 5,000 & 4,700 & 200 & 4,900 & 700 & 800 & 80 & 10 & 90 \\
\hline $\begin{array}{l}\text { Power Marketing } \\
\text { (PM) }\end{array}$ & 0 & $\cdots$ & 0 & 0 & 0 & 9,100 & 22,200 & 1,500 & 14,000 & 15,500 \\
\hline $\begin{array}{l}\text { Other Cognizant } \\
\text { Secretarial Offices }\end{array}$ & 0 & 0 & 200 & 0 & 200 & 100 & 600 & 100 & 1600 & 1700 \\
\hline Total & 138,000 & 140,900 & 43,600 & 94,200 & 137,800 & 25,400 & & 7,980 & 45,660 & 53,640 \\
\hline
\end{tabular}

- Excludes DOE wastes generated in support of the Naval Nuclear Propulsion Program and process waste water

** Includes byproduct material as defined in Section 11e(2) of the Atomic Energy Act of 1954, as amended

*** Includes RCRA-regulated, State-regulated, and TSCA-regulated.wastes 
Table 2.2 Department-Wide Generation Rates for 1991 through 1993 by Waste Type*

(Source: Annual Report on Waste Generation and Waste Minimization Progress)

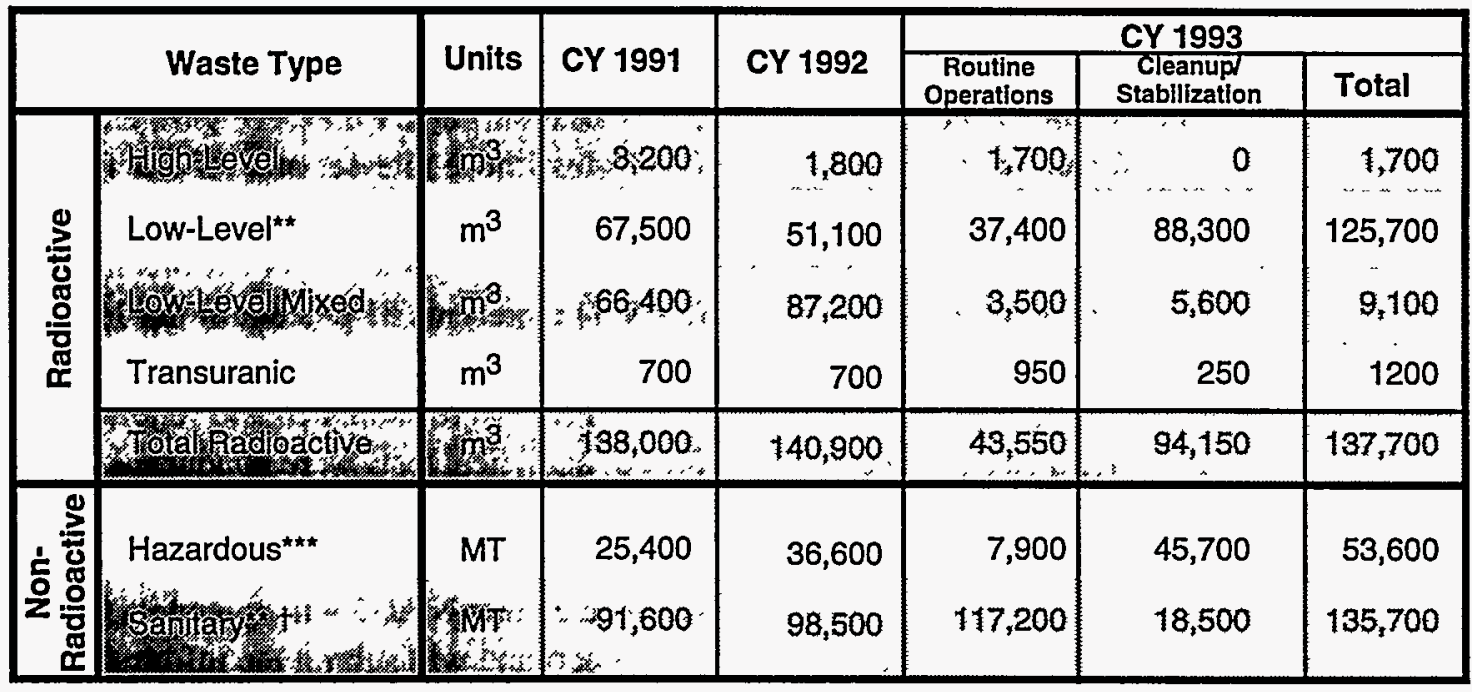

* Excludes DOE wastes generated in support of the Naval Nuclear Propulsion Program and process waste water

** Includes byproduct material as defined in Section $11 \mathrm{e}(2)$ of the Atomic Energy Act of 1954, as amended

*** Includes RCRA-regulated, State-regulated, and TSCA-regulated wastes

$\dagger$ Amounts recycled are not included in these totals

Figure 2.1 shows that 85 percent of the hazardous waste and 66 percent of the radioactive waste reported in 1993 are wastes retrieved from environmental restoration program cleanup/stabilization activities.

The recorded generation rate of sanitary waste has been increasing in part because of better tracking by

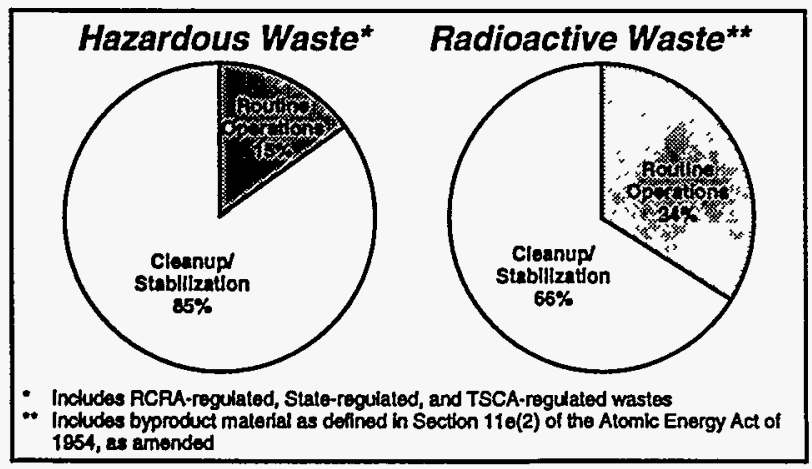

Figure 2.1 1993 Percentages of Roustine Operations and Cleonup/Stabilization Wasie Generation for Hazardous and Radioactive Waste Types (Source: 1993 Annual Report) sites. A significant amount of this waste has been diverted from landfills due to increased recycling efforts. In 1992, approximately 20 percent, or 24,000 metric tons, of sanitary waste was recycled. In 1993, sanitary waste recycling increased to 60,000 metric tons (approximately one third of the total generated).

\subsubsection{Toxic Chemical Release Invenfory Report Findings}

Executive Order 12856 directs all Federal agencies to comply with EPCRA and the Pollution Prevention Act of 1990. In addition, the Order directs each Federal agency to set a voluntary goal to reduce its total releases and off-site transfers of EPCRA Section 313 listed toxic chemicals 50 percent by the end of 1999 .

As a result of its commitment in 1992 to voluntary Toxic Chemical Release Inventory (TRI) reporting, DOE initiated early reporting and has established 
CY 1993 as its baseline year for measuring progress toward the reduction goal. The DOE 1993 baseline total of releases to the environment and off-site transfers for treatment and disposal was 4,677,836 pounds. Sites submit TRI reports for each chemical based upon whether they manufacture, process, or otherwise use that chemical above a threshold amount ( 25,000 or 10,000 pounds). Because 23 DOE sites reported in 1993, and because the number of sites reporting in the future may increase or decrease, the Department will measure its progress not on the number of facilities reporting, but on total pounds reduced across the complex (as reported in the TRI) compared to the 1993 baseline.

To achieve the 50 percent reduction goal by the end of 1999, DOE will need to focus efforts on the specific chemicals and sites which contributed the largest amounts to the 1993 baseline. Figure 2.2 identifies the respective percentages of the total
1993 reported quantity for the six largest contributing chemicals. Methanol represents 78 percent of all the toxic chemicals DOE reported as released to the environment or transferred off-site for treatment or disposal during CY 1993. Figure 2.3 shows the DOE sites whose releases and off-site transfers constituted more than 1 percent of DOE's 1993 baseline. Notably, the Naval Petroleum Reserve \#1 (NPR-1) represents 81 percent of the 1993 DOEwide TRI total. After CY 1993 methanol quantities from NPR-1 were estimated and reported to EPA, further analytical tests were conducted which determined that the release values were actually about 90 percent lower than originally reported. It is expected that NPR-1 will amend its CY 1993 TRI report and will submit the information to EPA for inclusion in the TOXNET database. Excluding NPR-1, the Idaho National Engineering Laboratory (INEL) accounts for 41 percent of the TRI total remaining. Complete DOE TRI data are available

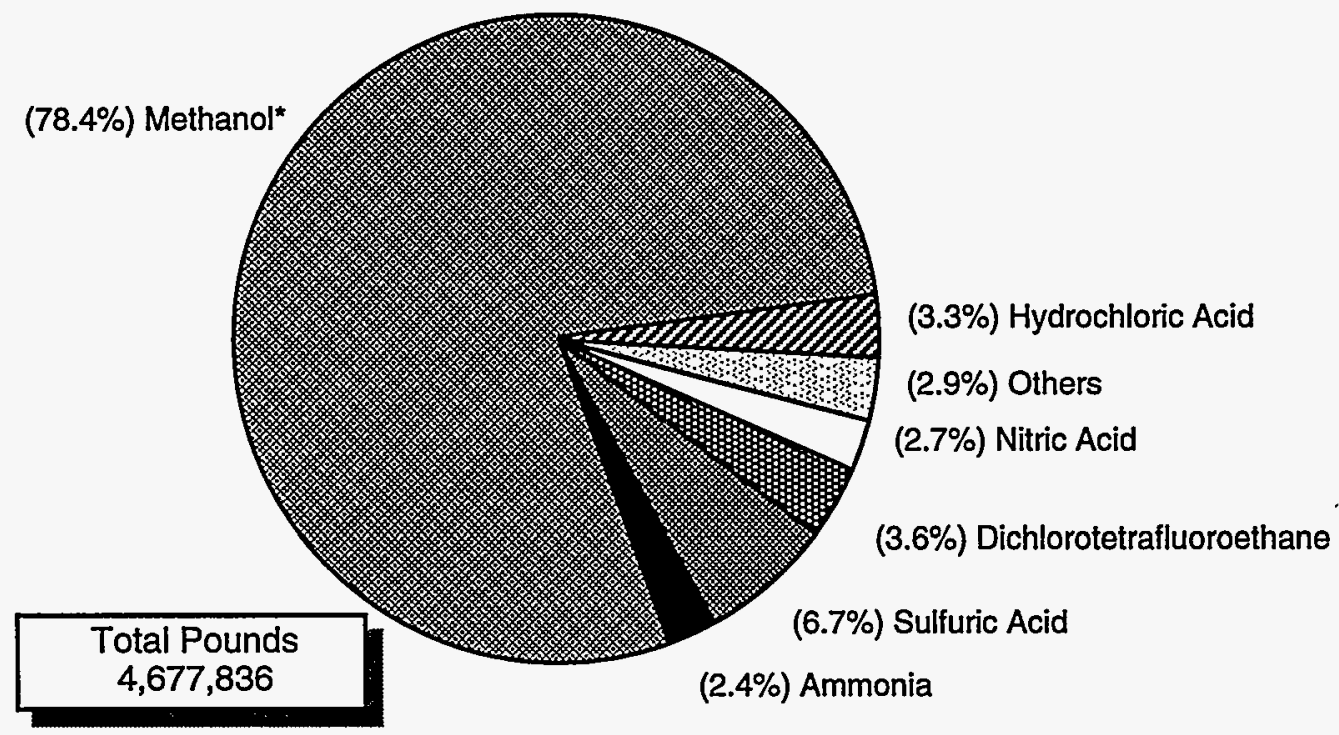

^NPR-1 methanol quantities were overestimated by 90 percent.

Figure 2.2 CY 1993 DOE Facility Releases and Transfers for Treatment and Disposal by TRI Chemical

(Source: TOXNET) 


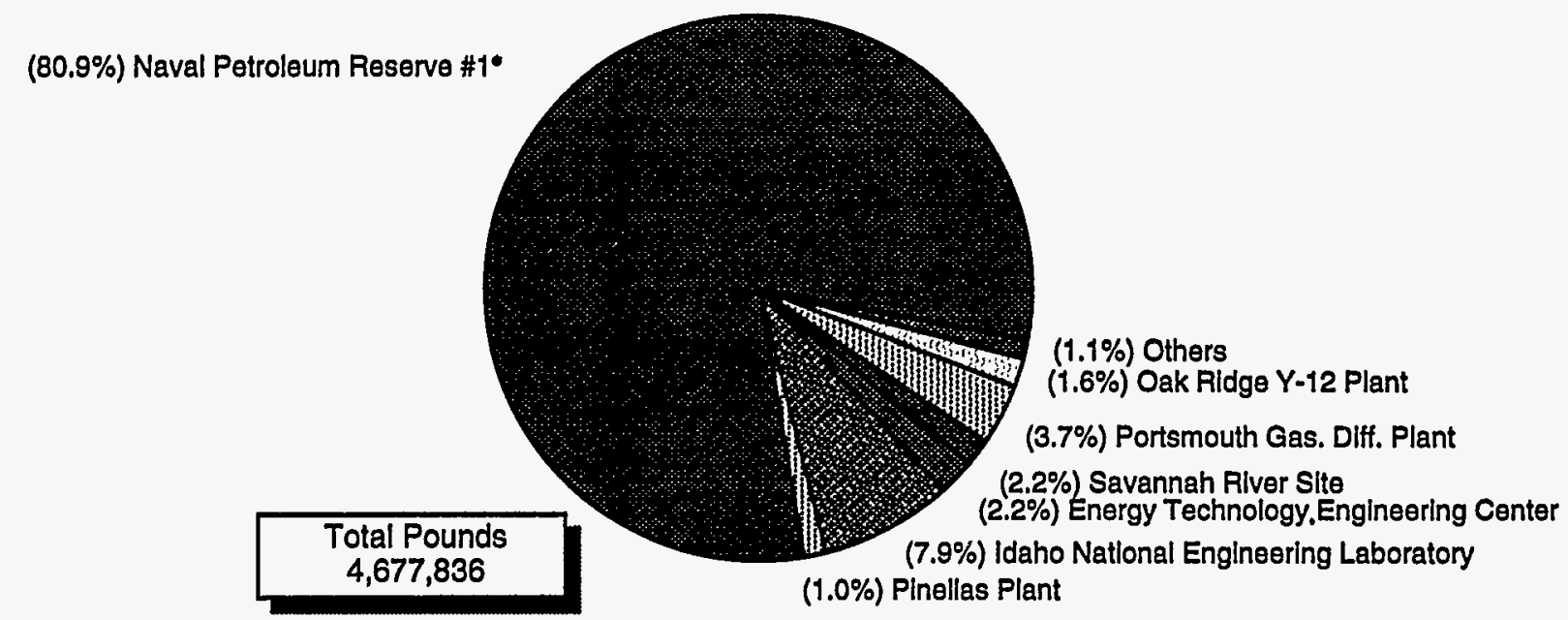

"NPR-1 methanol quantities were overestimated by 90 percent.

\section{Figure 2.3 CY 1993 DOE Facility Releases and Transfers of TRI Chemicals for Treatment and Disposal by Site} (Source: TOXNET)

on the Internet at http://www.eh.doe.gov/oepa/ facility/tri/tri_data.htm. To access these data, readers must use a PDF viewer such as Acrobat Reader.

\subsubsection{Draft 1996 Baseline Environmental Management Report (BEMR) Findings}

The draft 1996 BEMR contains projections of total waste volumes and management costs resulting from the activities of EM and other Departmental organizations over the life of the cleanup effort.

Waste reported in the draft 1996 BEMR can be divided into two main categories, 1) waste processed by the Office of Waste Management (EM-30), and 2) waste processed by the Office of Environmental Restoration (EM-40) and the Office of Nuclear Material and Facility Stabilization (EM-60). Waste processed by EM-30 is further divided into 3 sub-categories: 1) inventory and future EM-30 generated waste, 2) future EM-40/60 generated waste, and 3) future waste generated from non-EM DOE sources. Figure 2.4 compares the projected volumes between 1995 and 2070 for each waste type, including spent nuclear fuel, to each of the waste categories. Table 2.3 lists the actual quantities.

The data clearly indicate that more than two thirds of the waste generated over the duration of the cleanup effort will ultimately result from environmental restoration, decommissioning, and facility stabilization activities. Of this amount, more than 80 percent will be low-level waste and nearly 10 percent will be hazardous waste. Therefore, these areas may offer the greatest opportunity for pollution prevention activities. 


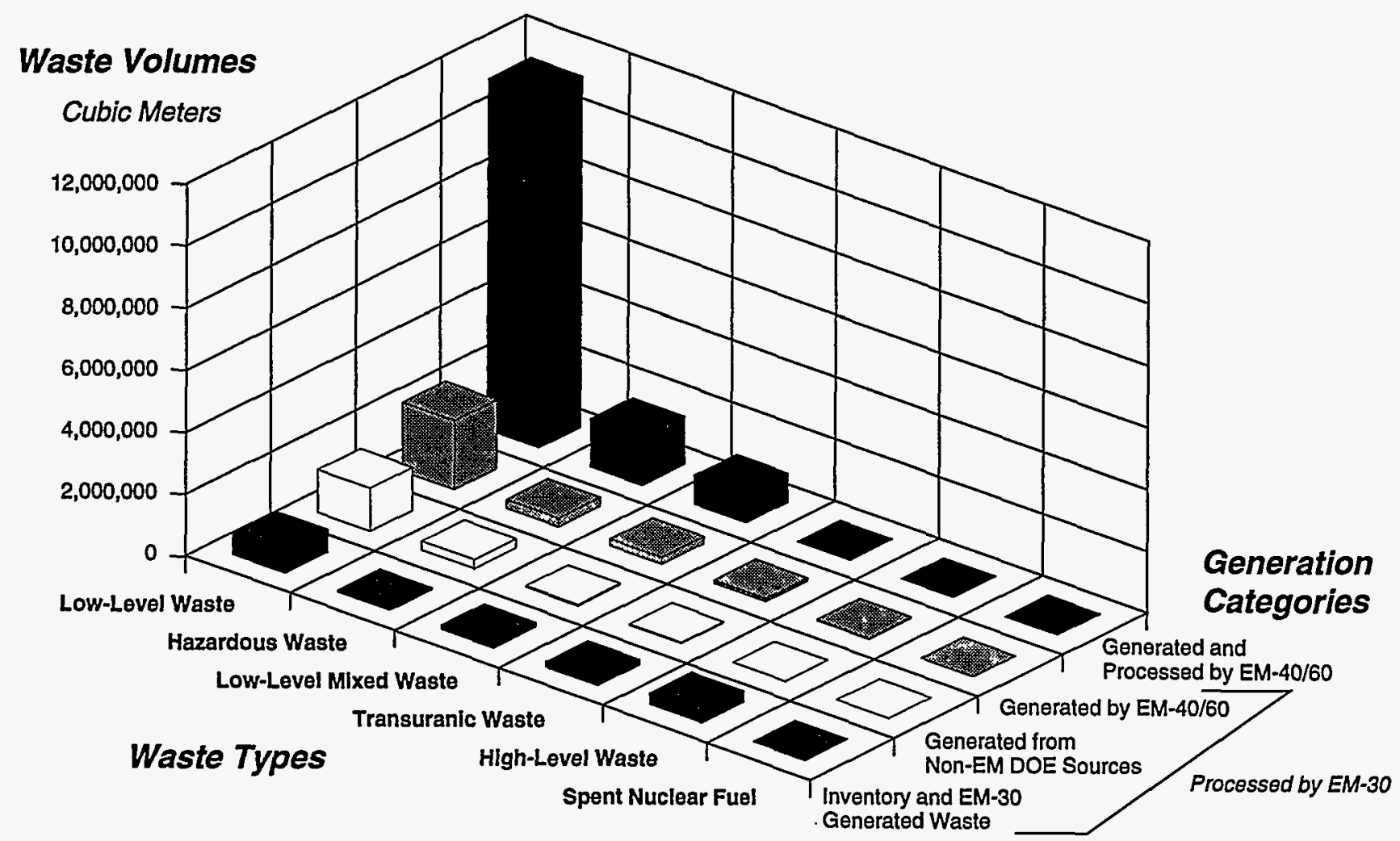

Figure 2.4 Projected Total Waste Volumes by Waste Type and Generation Calegory During the lifetime of the Cleanup Effort (Source: Draff 1996 Baseline Environmental Management Report)

Table 2.3 Draff 1996 BEMR Projected Waste Volumes During the Lifetime of the Cleanup Effort* (Cubic Meters)

\begin{tabular}{|c|c|c|c|c|c|}
\hline \multirow[b]{2}{*}{ Waste Type } & \multicolumn{3}{|c|}{ Waste Processed by EM-30 } & \multirow{2}{*}{$\begin{array}{c}\begin{array}{c}\text { Waste Processed } \\
\text { by EM-40 or } \\
\text { EM-60 }\end{array} \\
\text { Future } \\
\text { Waste Generated } \\
\text { by EM-40/60 }\end{array}$} & \multirow[b]{2}{*}{ Totals } \\
\hline & $\begin{array}{c}\text { Inventory and } \\
\text { Future EM-30 } \\
\text { Generated } \\
\text { Waste } \\
\end{array}$ & $\begin{array}{c}\text { Future } \\
\text { EM-40/60 } \\
\text { Generated } \\
\text { Waste } \\
\end{array}$ & $\begin{array}{c}\text { Future Waste } \\
\text { Generated } \\
\text { from Non-EM } \\
\text { DOE Sources }\end{array}$ & & \\
\hline High-Level Waste & 351,882 & 37,715 & 2,920 & & 392,517 \\
\hline Spent Nuclear Fuel & 2,584 & & 424 & & 3,008 \\
\hline Transuranic Waste & 157,323 & 93,980 & 32,406 & 3,100 & 286,809 \\
\hline Low-Level Waste & 717,648 & $2,229,660$ & $1,394,043$ & $11,267,000$ & $15,608,351$ \\
\hline Low-Level Mixed Waste & 136,944 & 221,530 & 45,685 & 928,000 & $1,332,159$ \\
\hline Hazardous Waste & 45,822 & 286,715 & 290,039 & $1,552,474$ & $2,175,050$ \\
\hline Total & $1,412,203$ & $2,869,600$ & $1,765,517$ & $13,750,574$ & $19,797,894$ \\
\hline
\end{tabular}

*Does not include sanitary waste, wastewater, uranium or mill tailings. Does include RCRA-, State-, \& TSCA-regulated waste. 


\subsection{DOE Waste-Related Costs}

Costs continue to rise as DOE treats, stores, and disposes of production, laboratory, and legacy wastes and performs environmental restoration activities. The draft 1996 BEMR projects the total waste management costs resulting from the activities of EM and other Departmental organizations over the next 75 years to be approximately $\$ 227$ billion. Funds expended prior to 1995 (approximately $\$ 30$ billion since the EM Program was established in October 1989) are not included in this cost estimate.

It is generally assumed that waste management and its resulting costs are the sole responsibility of EM. Two recent studies, however, one by Oak Ridge National Laboratory (ORNL) and one by Los Alamos National Laboratory (LANL), found that the generators can pay more than half of the lifecycle costs of low-level, hazardous, and sanitary waste treatment, storage, and disposal.

The ORNL report found that generators of hazardous waste are responsible for approximately 60 percent of the total handling and disposal costs. Such costs include procurement of the hazardous material; safety and health activities; usage and storage; and management, including maintenance, monitoring, characterization, and sampling.

The LANL study involved an analysis of costs associated with its management of low-level waste. The study determined that approximately 50 percent of those costs were borne by the generator. LANL's generator costs in this case included waste packaging, waste characterization, radiological survey, sampling and analysis, and transport documentation.

Based upon the two studies mentioned above, the costs of waste management to the generator should be considered when total waste management costs to the Department are analyzed. Generator organizations should seek mechanisms to identify and assign costs to each internal generator group.

The draft 1996 BEMR divides the EM Program into six activities: Waste Management, Environmental Restoration, Nuclear Material and Facility Stabilization Planning, Landlord, National Program Management and Planning, and Technology Development. These activities are described in detail in the draft 1996 BEMR, and the costs associated with these activities are summarized in Figure 2.5.

Waste management activities (waste storage, treatment, and disposal), after receipt from the generator, account for $\$ 111$ billion and represent the largest share (49 percent) of the total cleanup costs of $\$ 227$ billion. Environmental restoration has the next largest share ( 28 percent) of the total cleanup effort cost at $\$ 63$ billion. Consequently, the largest opportunity for pollution prevention exists within these two segments.

\subsection{Pollution Prevention Investments by Sites and $\mathrm{CSO}_{\mathrm{s}}$}

Sites receive pollution prevention funding through a variety of mechanisms. In the past, most of the funding came from overhead accounts and could not be directly tracked as pollution prevention funds. Table 2.4 shows total DOE budgets directly recorded on Activity Data Sheets (ADSs) and discretionary funds identified in the Environment, Safety and Health (ES\&H) Management Plan. In FY 1995, pollution prevention funds were identified for the first time in the ES\&H Management Plan. The purpose was to allocate funds for these programs. Because the majority of these funds are considered overhead or discretionary funds, most are not dedicated specifically for pollution prevention activities, although they are "targeted" toward them. 


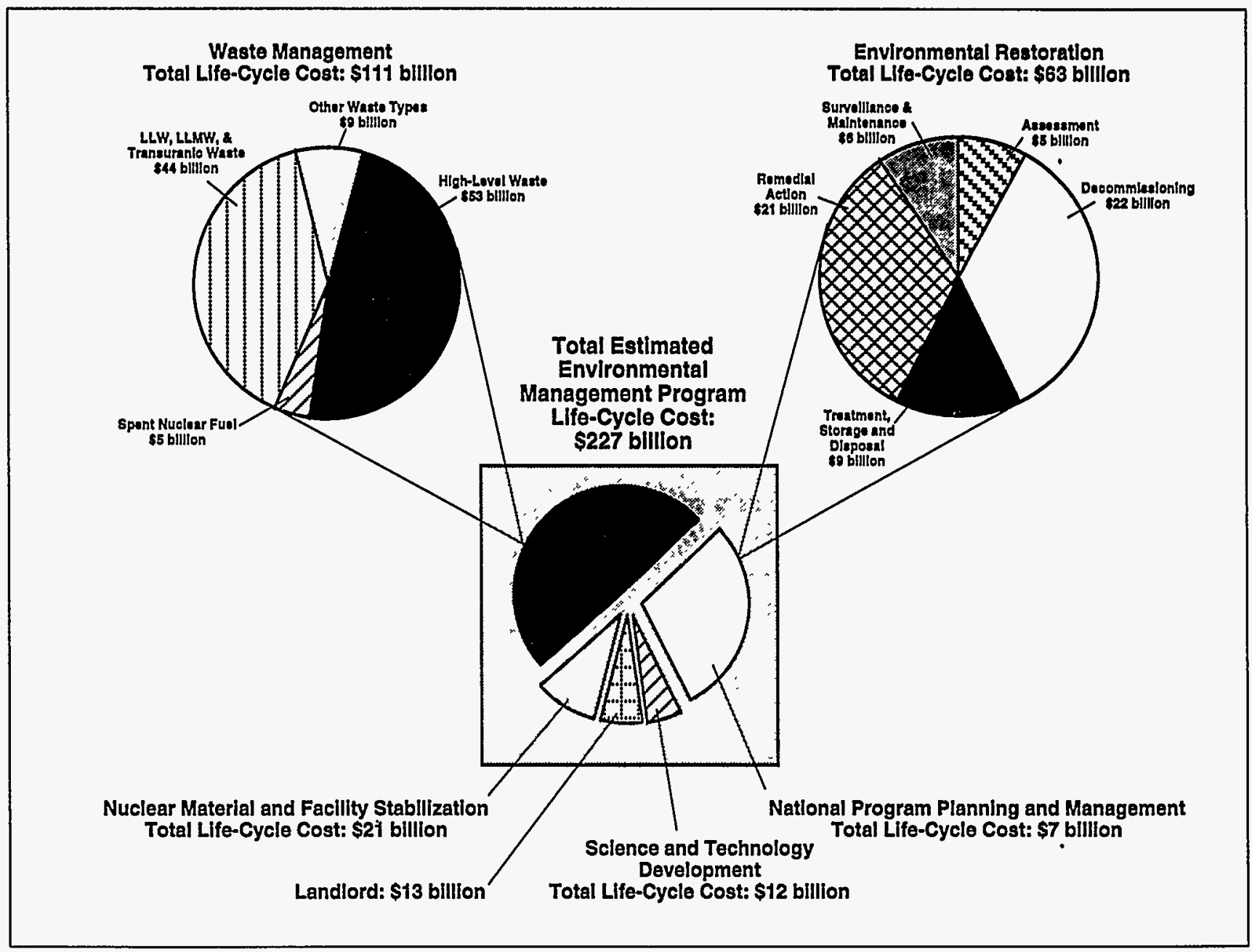

Figure 2.5 Projected Cost Estimates for the Life of the Environmental Management Program (Source: Draft 1996 Baseline Environmental Management Report)

The Department of Energy allocated 35 percent, or $\$ 5.8$ billion, of its $\$ 17.2$ billion FY 1995 budget for EM activities. Defense Programs activities account for $\$ 3.7$ billion, while Energy Research activities account for $\$ 2.7$ billion. In FY 1995, approximately 0.52 percent, or $\$ 30.3$ million, of DOE's budget directly funded pollution prevention programs (see Table 2.4).

\section{5 - Strengths of the Overall DOE Pollution Prevention Program}

Headquarters pollution prevention strengths lie in overall program planning, coordination, and evaluation. The Waste Reduction Steering Committee, which comprises representatives from all Headquarters offices, was established in July 1988 by DP to develop a pollution prevention program and provide guidance to sites. The Pollution Prevention Executive Board, consisting of all CSOs; was established in 1992 to provide overail Departmental leadership and direction for pollution prevention. The Executive Board will be chaired by the Under Secretary in 1996. Through the leadership of the Executive Board, DOE established a pilot Return-on-Investment (ROI) program that provided project-specific funding in 1994 to 
Table 2.4 Total DOE Dedicated Pollution Prevention Budgets for FY $95 \& 96$ (\$Milions)

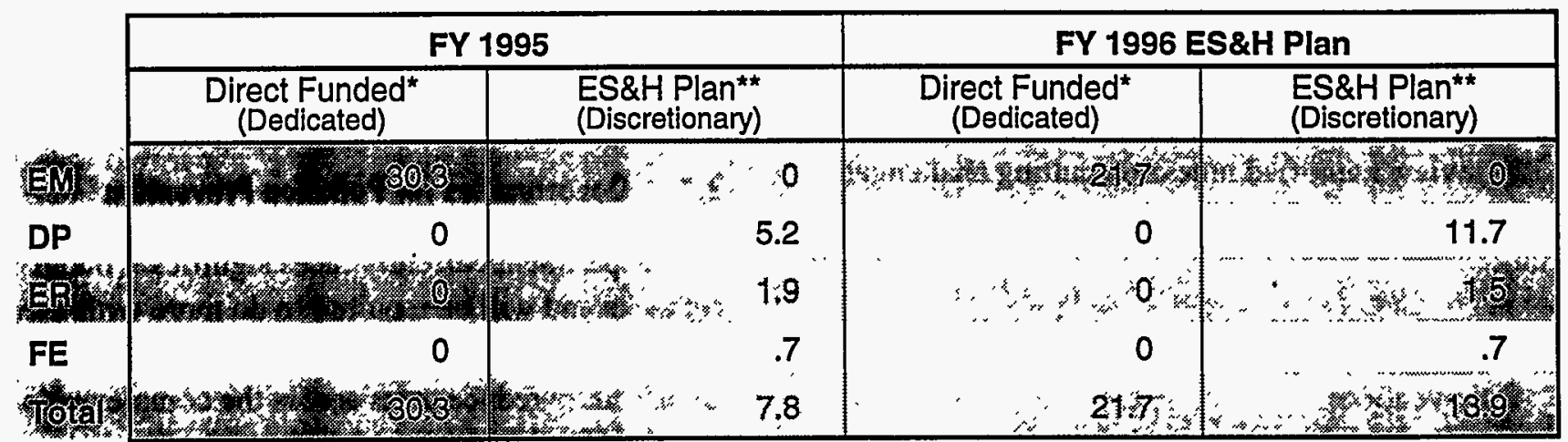

- Dedicated funds identified by separate B\&R Codes and ADSs; funds are directly under the control of DOE Operations Office Waste Minimization Coordinators.

** Funds identified in ES\&H Management Plan. Funds are not formally monitored by or under the direction of waste minimization coordinator staff in the field; benefits of funding are largely not documented.

implement pollution prevention activities that will yield significant cost savings in the short term. The Board elected to continue this program in 1995.

The DOE Pollution Prevention Strategy was approved by the Secretary and submitted to EPA on December 27, 1994 (see Appendix B). This document outlines the steps that DOE has taken and will take to implement Executive Order 12856 and other environmental Executive Orders. The Department is positioned to implement the strategy through its established and expanding pollution prevention program infrastructure.

Site pollution prevention strengths lie in program development, awareness, and technical support. Sites have been building programs, encouraging source reduction and recycling, and reporting progress to Headquarters in their site plans and annual waste reduction reports mentioned above. The success of site programs is due in large part to the dedication of the waste minimization coordinators and support staff. Most of the accomplishments to date are a result of grassroots efforts by staff who champion the benefits of pollution prevention.
Pursuant to DOE Order 5400.1, DOE has required the preparation of site Pollution Prevention Awareness Plans (site plans) and annual waste reduction reports since 1989.

The DOE pollution prevention program relies on the establishment and maintenance of strong site programs with commitment and support from Headquarters. The success of the overall program hinges on the ability of the sites to reduce pollutant generation and increase recycling rates, following the implementation strategy presented in Section 3. Many sites have already achieved positive results from implementing pollution prevention programs.

\subsection{Challenges to Implementing a Complete Program}

The Deputy Assistant Secretary for Environment, Office of Environment, Safety and Health, authorized the Office of Environmental Audit to conduct a Special Issue Review of Pollution Prevention Management within the Department of Energy (Special Issue Review), due to the importance of pollution prevention in meeting Departmental and national environmental performance goals. This review, although now over 1 year old, highlights 
the ongoing challenges facing DOE, and illustrates areas where DOE is working to enhance its programs.

The review identified nine crosscutting challenges that impede program development and implementation:

- awareness and understanding of pollution prevention;

- management commitment;

- organizational issues;

- financial incentives and disincentives;

- pollution prevention funding prioritization;

- integration into environmental restoration;

- technical assistance;

- moratorium on offsite shipment of waste; and

- changing mission.

The review also found that most of the DOE pollution prevention funding has been allocated to program development activities and very little for project implementation. Today, a major barrier impeding the DOE pollution prevention program is the inadequacy of generator involvement in site planning and the shortage of generator project funds to implement pollution prevention opportunities.

A complete copy of the Special Issue Review can be obtained through the DOE Office of Environmental Audit, Office of Environment, Safety and Health (DOE/EH-0421) and is available via
Internet at http://epic.er.doe.gov/epic.htm. The findings from the review are summarized in Appen$\operatorname{dix}$ C.

\subsection{Opporfunities for Pollution Prevention}

The Department currently faces significant budget cutbacks and will be required to do more with less. Pollution prevention offers an opportunity to significantly reduce costs across the complex. With effective funding and implementation of pollution prevention programs, it is reasonable to expect cost savings in the billions of dollars.

DOE's challenge to improve its operational efficiency with continually shrinking funds calls for the identification of the best long-term pollution prevention opportunities throughout the complex. Incorporating pollution prevention into new project design provides one of the greatest opportunities. Up to 80 percent of project costs are committed during the conceptual design and design engineering phases, while less than 10 percent of the costs have been incurred. Designing for pollution prevention ensures that actions implemented early in the life cycle of a project have the greatest impact on reducing waste volumes and/or management costs. The earlier such actions are taken, the greater the potential for savings.

It is clear that both waste reduction and cost savings can be realized by pollution prevention across DOE. Such savings would be partially offset by implementation costs of pollution prevention projects, but rates of return on a pollution prevention investment could reach 100 percent or higher. These potential savings offer a strong incentive to proceed aggressively with pollution prevention programs. 


\subsection{IMPLEMENTATION GUIDANCE}

All DOE sites should perform the activities outlined in the Activity Plan presented below. However, following Operations Office guidance, small DOE sites may implement those portions of the Activity Plan appropriate to the size and scope of their operations such that there is value added to the activities implemented for the costs incurred. For purposes of this plan, a small site is defined as one whose waste generation falls below the thresholds listed in Table 3.1. Operations Offices can use Table 3.1 as guidance to determine the appropriate level of implementation for each site.

\subsection{Waste Minimization/Pollution Prevention Activity Plan}

The 1994 Waste Minimization/Pollution Prevention Crosscut Plan set the course for implementation throughout the complex through development of an Activity Plan, which contained 18 key activities to be completed by CY 2000. This plan describes the Department's progress in implementing the $18 \mathrm{key}$ activities, and sets priorities to expedite Departmental pollution prevention implementation.

Figure 3.1 shows the work breakdown structure of the Activity Plan with specific activities to support each initiative. The 18 activities are grouped into three broad areas of responsibility: policy direction, infrastructure development, and program implementation. Policy direction commits the Department to pollution prevention as the primary strategy for environmental management. Infrastructure development provides the framework for effective programs and projects. Program implementation calls for changes in processes, equipment, and operations at DOE's facilities and sites to reduce waste generation and environmental releases, or increase recycling.

A narrative description of the Activity Plan is provided in Appendix D. Further details are available in the 1994 Crosscut Plan.

\subsection{Waste Minimization/Activity Plan Implementation Strategy}

Although some progress was made in 1994 and 1995 to implement the 18 activities identified in Figure 3.1, it became clear that implementation priorities were needed to expedite the Department's pollution prevention progress. This plan identifies six immediate priorities, described in detail below, that will focus site and Headquarters efforts on achieving aggressive reductions in DOE waste generated and pollutants released. These immediate priorities are to be completed by FY 1998.

Table 3.1 Small Site Implementation Criteria*

\begin{tabular}{|l|c|}
\hline \multicolumn{1}{|c|}{ Waste Type } & Annual Waste Generation Threshold \\
\hline Low-Level & 50 cubic meters \\
\hline Mixed & 1 cubic meter \\
\hline RCRA-Regulated & 10 metric tons \\
\hline TSCA-Regulated & 10 metric tons \\
\hline
\end{tabular}

* Criteria for judging whether DOE sites are sufficiently small as to be exempt from performing activities contained in this plan. 


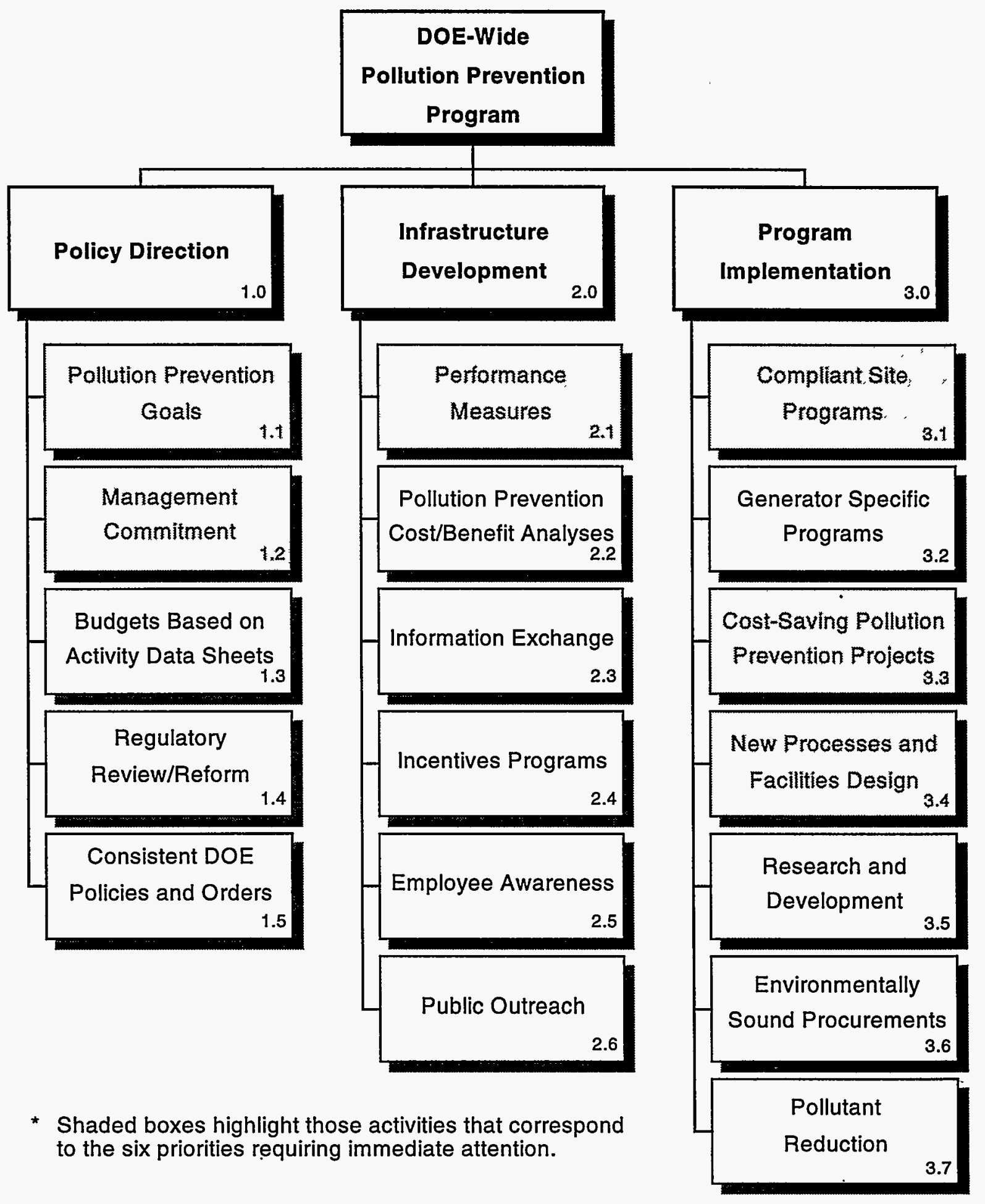

Figure 3.1 Work Breakdown Siructure of DOE's Pollution Prevention Program 
This plan further separates the remaining 12 activities into 6 near-term priorities and 6 out-year activities, to be completed by FY 1999 and FY 2000 , respectively (see Section 3.3).

\subsubsection{Priority 1: Establish Senior Management Commitment}

Strong and visible senior management commitment is necessary for a successful DOE-wide pollution prevention program. This plan encourages managers within Headquarters (Office Directors and above), Operations Offices, laboratories, and site contractor organizations to show commitment to pollution prevention by doing what is necessary to achieve the Secretarial goals shown in this plan, and implementing, where cost effective, the activities of this plan. Senior management can demonstrate its commitment to pollution prevention in the following ways: building pollution prevention into "mainline" documents, establishing clearly defined expectations and goals, establishing accountability, providing adequate resources, and overseeing initiatives and performance. Management should budget for pollution prevention activities per unit of waste generated or per full-time equivalent (FTE) employee. Senior DOE management should also extend accountability to site contractors. Prime contractors at each site should have similar pollution prevention commitments; the accomplishment. of pollution prevention goals and milestones should be included in the criteria for the contractors' performance and award fees.

\subsubsection{Priority 2: Set Quantitative Source Reduction and Recycling Goals}

The Secretary of Energy has committed the Department to achieving the source reduction and recycling goals shown in Table 3.2 by the end of 1999.

Table 3.2 Departmental Source Reduction and Recycling Goals, Compared to the 1993 Baseline of Waste Generation

\begin{tabular}{|c|c|c|c|}
\hline Goal & 1993 Baseline & $\begin{array}{c}\text { By } \\
\text { December } \\
31,1999 \\
\end{array}$ & $\begin{array}{c}\text { Type of Waste } \\
\text { Generation } \\
\text { Activity }\end{array}$ \\
\hline 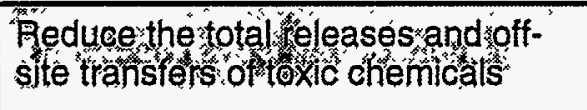 & $4,677,836 \mathrm{lbs}$ & 50 & (notino orations \\
\hline $\begin{array}{l}\text { Reduce generation of hazardous } \\
\text { waste }\end{array}$ & $7,921 \mathrm{MT}^{\star \star}$ & $50 \%$ & Routine Operations \\
\hline $\begin{array}{l}\text { Reduce generattẹn of radioactive* } \\
\text { waste }\end{array}$ & $37,392 m^{3}$ & & \\
\hline $\begin{array}{l}\text { Reduce generation of low-level } \\
\text { mixed waste }\end{array}$ & $3,524 \mathrm{~m}^{3}$ & $50 \%$ & Routine Operations \\
\hline 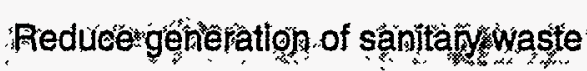 & & & Boutine oporations \\
\hline $\begin{array}{l}\text { Divert sanitary waste } \\
\text { for recycling }\end{array}$ & $N A^{* \star *}$ & $33 \%$ & $\begin{array}{c}\text { Routine Operations } \\
\text { and } \\
\text { Cleanup/Stabilization }\end{array}$ \\
\hline 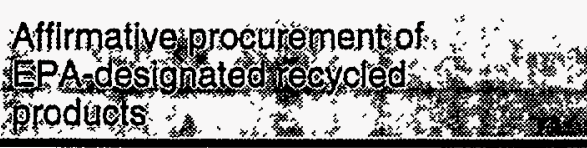 & $2 x-3 x$ & & \\
\hline
\end{tabular}

* Represents low-level waste only.

** Includes RCRA-regulated, state-regulated and TSCA-regulated wastes.

*** Recycling and affirmative procurement baselines are established annually. 
Setting quantitative source reduction and recycling goals and directing funds to achieve those goals are essential to the DOE pollution prevention program. Goals provide management with tangible targets, and a basis for measuring progress. Goals promote cooperation among sites, Operations Offices, and CSOs as managers work together to achieve a common purpose. Without goals, various entities within the sites and at Headquarters are not challenged to work together to prevent pollution.

In accordance with Executive Order 12856, the Department will achieve, by December 31, 1999, a 50 percent reduction from CY 1993 levels in total releases of EPCRA 313 toxic chemicals to the environment, and off-site transfers of such chemicals for treatment and disposal from routine operations, as reported in DOE TRI reports. This builds upon DOE's voluntary goal of reducing priority TRI chemicals 33 percent by 1997 as part of EPA's 33/50 Program. These reductions will be achieved to the maximum extent practicable through source reduction. Source reduction can be achieved through process and procedural changes and by eliminating or reducing the unnecessary acquisition of products containing toxic chemicals. One way to accomplish this is to review specifications and standards to identify opportunities to eliminate or reduce the use of toxic chemicals. Accordingly, Operations Offices should direct that each appropri- ate site develop a plan and goals to reduce or eliminate the unnecessary acquisition of products containing toxic chemicals.

The Department also commits to achieve, by December 31, 1999, a 50 percent reduction in radioactive, mixed, and hazardous waste generated in routine operations, based upon the 1993 baseline. These goals will be achieved through source reduction and recycling. The Department further commits to achieve a 33 percent reduction in the generation of sanitary waste through the end of 1999 , based on the 1993 baseline. This goal can only be achieved through source reduction because sanitary waste generation, as reported in the Annual Report, is measured as the amount of waste that remains after recycling.

To satisfy a requirement of Executive Order 12873, the Department will purchase 100 percent of those recycled items designated by the EPA, except where the items are not available competitively at a reasonable price within a reasonable time frame, or if they do not meet appropriate performance standards. Purchasing non-recycled versions of the EPA-designated items will require written justification citing one or more of the above conditions.

Should the Department be successful in achieving its reduction goals for routine operations, DOE

Table 3.3 Projected Annual Cost Savings to be Realized by Achieving Secretarial Goals

\begin{tabular}{|l|c|c|c|}
\hline \multicolumn{1}{|c|}{ Waste Type } & Annual Avoided Waste & Preliminary Unit Costs* & $\begin{array}{c}\text { Annual Savings } \\
\text { (\$millions) }\end{array}$ \\
\hline Hazardous** & $4,015 \mathrm{MT}$ & $\$ 8,400 / \mathrm{MT}$ & $\$ 33.7$ \\
\hline Low-Level Radioactive & $18,450 \mathrm{~m}^{3}$ & $\$ 1,300 / \mathrm{m}^{3}$ & $\$ 24.0$ \\
\hline Low-Level Mixed & $3,642 \mathrm{~m}^{3}$ & $\$ 11,000 / \mathrm{m}^{3}$ & $\$ 40.1$ \\
\hline Sanitary & $38,666 \mathrm{MT}$ & $\$ 200 / \mathrm{MT}$ & $\$ 7.7$ \\
\hline
\end{tabular}

* Radioactive waste costs are based upon Report INEL-94/0250 of variable costs (excluding fixed operating costs) from four representative sites. Non-radioactive waste costs are based on information from several sources compiled by the Office of Pollution Prevention. Actual costs could vary among sites.

** Includes RCRA-regulated, state-regulated, and TSCA-regulated wastes. 
would save $\$ 106$ million yearly in avoided waste management costs beginning in 2000 . This would be a significant efficiency gain; money that otherwise would have been spent treating and disposing of waste would then be available for mission activities. These potential savings are presented in Table 3.3. Cumulative escalated cost savings from achievement of goals over the 10-year period 19962005 could exceed $\$ 900$ million. These cost savings, shown in Figure 3.2, assume that DOE will make uniform progress in each of the 4 years between 1996 and 1999, inclusive, to achieve its reduction targets.

As shown in Section 2.2.3, the draft 1996 BEMR suggests that current inventory and routine operations waste generation represent only 7 percent of the total waste volume that will be processed by the Department over the next 75 years. Application of pollution prevention to DOE's cleanup/stabilization programs is expected to yield significantly larger

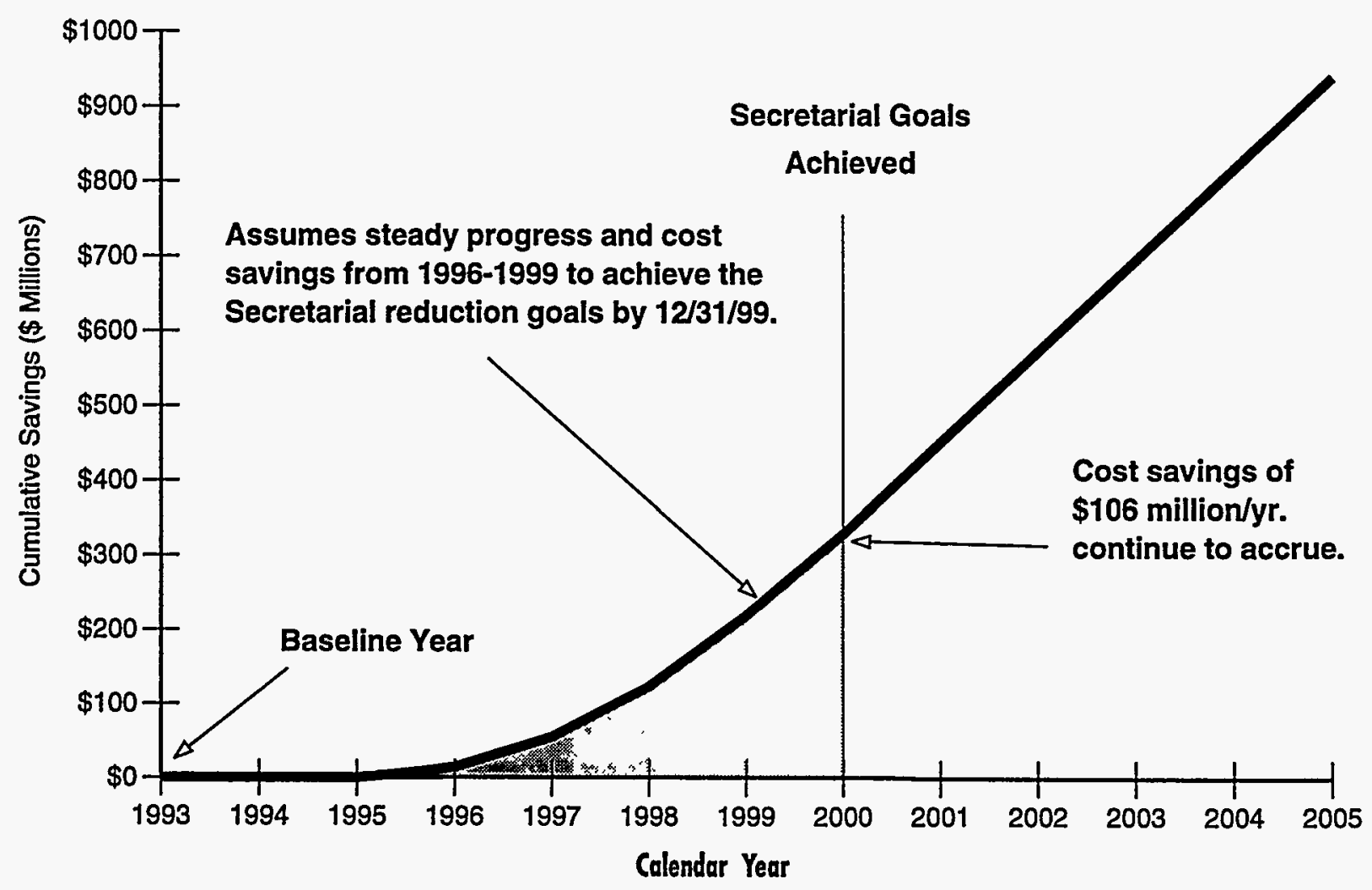

Figure 3.2 Cumulative Cost Savings to the Department from Achievement of Secretarial Goals cost savings than the near-term, routine-waste-only savings shown in Figure 3.2. Studies are currently underway to determine how best to apply pollution prevention to cleanup/stabilization programs.

The Department recognizes that numerical reduction goals cannot be established for cleanup/stabilization wastes as generation of these waste volumes will continue as cleanup proceeds. Progress can instead be measured by recycling percentages achieved. Therefore, the Department's goal is to divert for recycling 33 percent, by weight, of its sanitary waste stream by the end of CY 1999. This recycling goal applies to all DOE wastes, including routine operations waste and cleanup/stabilization waste.

The Department will report annually to the Secretary, to EPA, and to the Federal Environmental Executive, progress made in achieving its TRI, source reduction, recycling, and affirmative procurement goals. 


\subsubsection{Priority 3: Institute Performance Measures}

Pollution prevention performance measures provide essential feedback to management on progress made toward achieving goals. They also allow for program readjustment if progress is considered inadequate.

Departmental pollution prevention performance measures must be relevant, understandable, verifiable, and comparable. One performance measure should be to quantify the amount of pollution avoided as a result of pollution prevention activities.

The heart of the issue is how to provide a meaningful link between pollution generation data and pollution prevention activities at the sites. Pollution prevention progress based on overall changes in pollutant generation will be overestimated when a facility has reduced activity or has shut down completely, as has happened at many DOE sites. Conversely, activities such as environmental restoration, by their very nature, result in significant increases in pollutants that must be handled. Measuring individual activities and then summarizing the changes in pollutant generation due to pollution prevention, project-by-project, is the most accurate way to assess the effectiveness of the pollution prevention program.

This plan establishes two categories of pollution prevention measures that DOE laboratory and contractor sites should consider putting in place between now and FY 1998. The first involves performance measures for pollution prevention in routine operations only (Table 3.4). The second (Table 3.5) involves measures for pollution prevention in all operations (routine and cleanup/stabilization).

DOE sites already collect data for reporting against Secretarial waste reduction, recycling, and affirmative procurement goals and on Executive Board Return-On-Investment Projects. Beginning in
Table 3.4 Pollution Prevention Performance Measures Routine Waste Only

\begin{tabular}{|l|}
\hline \multicolumn{1}{|c|}{ Site Performance Measures } \\
\hline Volume of radioactive waste reduced* \\
Volume of mixed waste reduced * \\
Weight of hazardous and sanitary waste \\
reduced* \\
Weight of EPCRA 313 toxic chemical releases \\
and off-site transfers reduced * \\
Weight of toxic chemical releases and off-site \\
transfers reduced, project-by-project, due to \\
pollution prevention activities \\
*Secretarial Goal
\end{tabular}

Table 3.5 Pollution Prevention Performance Measures All Operations (Routine and Cleanup/Stabilization)

\begin{tabular}{|l|}
\hline \multicolumn{1}{|c|}{ Site Performance Measures } \\
\hline Total number of pollution prevention projects \\
completed in the reporting year, and project-by- \\
project implementation costs, wastes avoided, \\
and savings realized \\
Percentage of sanitary waste recycled * \\
Percentage of affirmative procurement \\
guideline materials purchased * \\
- Secretarial Goal
\end{tabular}

1996, sites will be requested to report these performance measures for DOE-wide collection and submittal to the Secretary in the Annual Report on Waste Generation and Waste Minimization Progress. Sites will also be requested to report. costs and savings on a project-by-project basis for all site pollution prevention activities.

Using Tables 3.4 and 3.5, Headquarters and Operations Office managers can make site-by-site comparisons by normalizing (dividing) appropriate 
performance measures against factors which relate to activities that directly or indirectly affect the quantity of waste being generated. The following site information should be useful in creating normalization factors:

- Total number of site employees.

- Total radioactive or hazardous waste generated at the site.

- Total projected treatment, storage, and disposal costs to manage site-generated waste.

Use of normalized comparisons, while not absolute, will establish important trends that, coupled with other site information, should allow sites to be judged relative to each other. For example, a site that budgets very little per employee on pollution prevention, and also makes very little percentile progress in reducing waste amounts, clearly must be challenged regarding its commitment to pollution prevention.

\subsubsection{Priority 4: Implement Cost-Saving Pollution Prevention Projects}

The main function of DOE's pollution prevention program is to reduce the generation of pollutants and increase the rate of recycling. Source reduction and recycling goals can only be achieved when pollution prevention projects are aggressively implemented. However, the implementation of such projects should proceed according to priority waste streams and economic return.

Pollution prevention projects should be implemented by the waste generating organization.
Traditionally, waste generators have been reluctant to reduce the generation of pollutants from their operations, even though process improvements would reduce the overall cost of DOE operations by reducing environmental management costs.

The return-on-investment program was initiated to demonstrate the economic benefit of implementing pollution prevention projects, focusing on those with high potential for reducing operational costs. The ROI program is based upon total cost savings achieved across all DOE organizations compared to the dollars spent to implement the projects. A case study of a successful ROI project is presented in Figure 3.3.

The Department's Pollution Prevention Executive Board initiated the ROI program in 1994 and expanded it in 1995 . The program is now considered sufficiently mature to be transferred to the sites for direct implementation. Sites should perform Pollution Prevention Opportunity Assessments (PPOAs) for all major waste streams and implement the most promising pollution prevention projects based on those assessments.

Various near-term funding sources for the ROI program are being evaluated as site programs are put in place. A potential funding source is the use of generator set-aside fees. Under this system, waste generators would be assessed a fee based on volume and toxicity of the pollutants generated. These fees would be used to fund the implementation of pollution prevention projects at the site where fees were collected. A pilot generator setaside program is currently being tested at various sites reporting to the Albuquerque, Oak Ridge, and Savannah River Operations Offices. 


\section{High Return on Investment (ROI) Project:}

Elimination of Radioactive Waste by Radioactive Material Management Area (RMMA) Shrinkage

Project Description: Building 9995 at the Oak Ridge Y-12 Plant currently has $19,000 \mathrm{ft}^{2}$ of floor area defined as a RMMA (essentially the entire building). All wastes leaving the building are considered low-level radioactive (LLW) for disposal. This project will reduce the overall size of the RMMA to 2,300 $\mathrm{ft}^{2}$ through work restructuring, decontamination, and relocating radiation area signs. The smaller area will mean less personal protective equipment (PPE) will be required for work activities and most material leaving the building will not be considered LLW.

Total Project Cost: $\quad \$ 295,535$

ROI: $340 \%$

BEFORE:

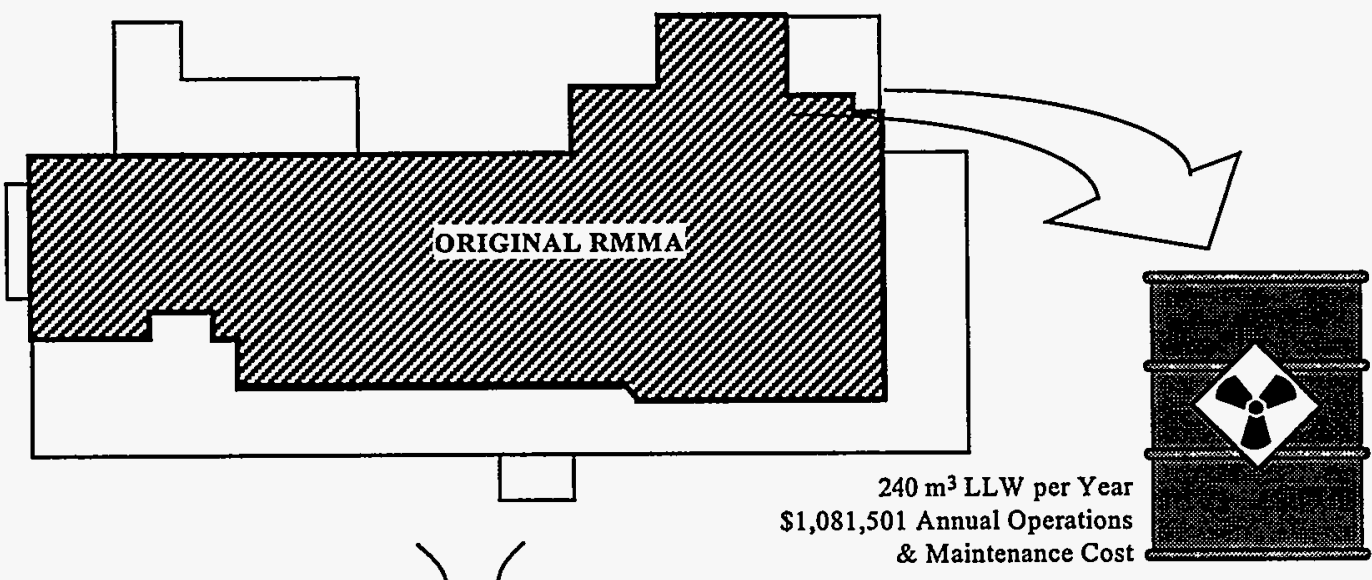

RMMA SHRINKAGE

AFTER:
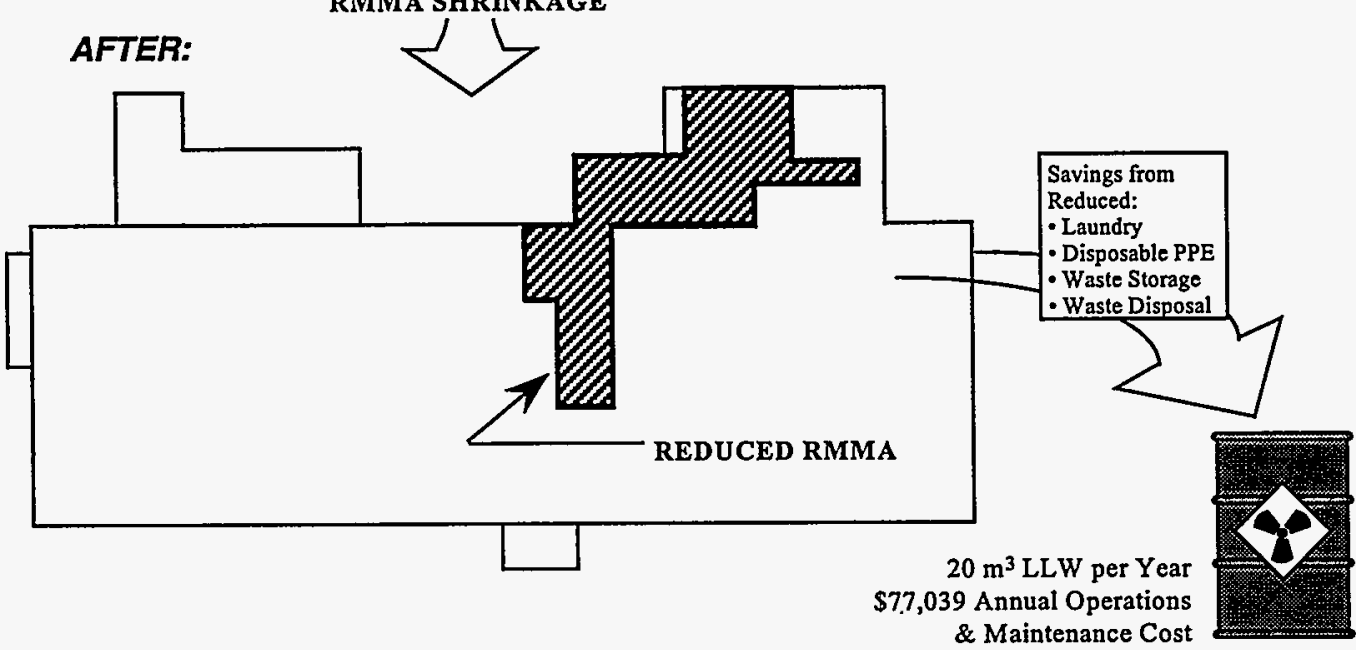

Total Project Cost: $\$ 295,535$

Return On Investment: $340 \%$

Annual Waste Reduction: $220 \mathrm{~m}^{3}$ LLW

Annual Savings: $\$ 1,004,462$

Projected Disposed Waste Reduction: $2,220 \mathrm{~m}^{3}$ LLW

Total Savings (NPV): $\$ 8,111,000$

Figure 3.3. Pollution Prevention Case Study: $\$ 300,000$ Investment Yields $\$ 10$ Million in Savings over 10 Years. 


\subsubsection{Priority 5: Design Pollution Prevention into New Products, Processes, and Facilities}

It is often difficult to cost effectively incorporate pollution prevention into ongoing DOE operations and activities. The most opportune time to incorporate pollution prevention is in the design phase of new products, processes, and facilities. Although it is never too late to consider preventing pollution, the earlier in design that pollution prevention is implemented, the greater the potential for benefits.

Design for pollution prevention should encompass the entire life cycle of a project. Materials used in construction and operation, energy efficiency of materials and processes, and environmental releases during operation and dismantlement should be considered. Mechanisms to implement pollution prevention in design include the use of Pollution Prevention Opportunity Assessments and "design for environment" methodologies modified to address the general design criteria for $\mathrm{DOE}$ projects.

The Pacific Northwest Laboratory published $A$ Proposed Framework for Conducting Pollution Prevention Design Assessments (P2DAs) on U.S. Department of Energy Projects in October 1994 (PNL-10204). The proposed method is a modification of the basic PPOA approach, tailored for DOE design projects. Incorporating pollution prevention into design is a five-step process that should be applied to each design stage. The steps are:

- identify and quantify waste streams anticipated during construction, operation, and closure or dismantlement of the process or facility;

- prioritize streams, set boundaries, and establish goals for the remainder of the design assessment;

- identify pollution prevention design opportunities;
- analyze design alternatives; and

- implement selected pollution prevention design opportunities and document results.

The Pacific Northwest National Laboratory, in collaboration with other Hanford contractors, also developed a document entitled, Design Pollution Prevention into New Products, Processes, and Facilities; a training course entitled An Orientation to Pollution Prevention for Facility Design; and a software program entitled Pollution Prevention Environmental Design Guide for Engineers (P2$E D G E$ ). These tools offer an integrated approach to incorporating pollution prevention strategies into new products, processes, and facilities to reduce lifecycle costs and increase material and energy efficiency.

The above tools can be obtained via the World Wide Web at either http://w3.pnl.gov:2080/dfe/ home.html. or http://epic.er.doe.gov/epic.htm.

\subsubsection{Priority 6: Ensure that Programs Comply with Federal, State, and Deparmental Directives}

DOE managers should place a high priority on implementing the DOE Pollution Prevention Strategy issued by the Secretary on December 27, 1994 (see Appendix B). The Secretary's strategy addresses the implementation of Executive Order 12856 and the other Executive Orders with pollution prevention requirements.

Following are the objectives of the DOE Pollution Prevention Strategy. Each objective is described in detail in Appendix B.

Objective 1 Effectively institutionalize the pollution prevention ethic through training and awareness in all mission areas. 
Objective 2 Reduce releases and off-site transfers of toxic chemicals to the environment.

Objective 3 Incorporate pollution prevention into the acquisition process.

Objective 4 Achieve emergency planning and community right-to-know reporting.

Objective 5 Address other environmental quality issues and pollution prevention focus areas.

Objective 6 Develop, transition, and apply innovative pollution prevention technologies.

In addition to their other compliance responsibilities, sites are encouraged to refer to the EPA's Waste Minimization National Plan for guidance when developing their site plans. This document identifies specific hazardous wastes as priorities for reductions; those priority wastes should be given special consideration when reduction goals are developed. This document is available from EPA's Office of Solid Waste and Emergency Response. The document number is EPA530-12-94-045, November 1994.

\subsection{Implementation Stałus}

The six priorities described earlier are part of the Activity Plan's 18 key activities that must be completed by FY 2000 for the Department to have a successful pollution prevention program. Figure 3.4 illustrates the sequence of activity implementation in order to meet that goal.

Because the 18 activities shown in Figure 3.4 are interdependent, all are necessary for a successful pollution prevention program. Sites should continue to fund programs each fiscal year on the full range of required activities. However, for purposes of budget submissions and establishing a completion schedule, this plan establishes three schedules, of 6 activities each, for aggressive implementation:

1. Immediate Priorities (FY 96-98)

- Management commitment

- Pollution prevention goals

- Performance measures

- Cost saving projects

- New processes and facility design

- Compliant site programs

2. Near-Term Priorities (FY 97-99)

- Generator specific programs

- Toxic pollutants and chemical reduction

- Budgets based upon Activity Data Sheets

- Pollution prevention cost/benefit analyses

- Information exchange

- Employee awareness

3. Out-year Activities (FY 98-2000)

- Environmentally sound procurement

- Research and development

- Consistent DOE policies and orders

- Public outreach

- Incentives programs

- Regulatory review/reform

For the six immediate priority activities, DOE is weakest in establishing performance measures for pollution prevention progress (Section 3.2.3) and designing pollution prevention into new facilities (Section 3.2.5).

Each Operations Office is encouraged to direct its reporting sites to plan for and implement the priorities identified in this plan, and to take corrective measures, as necessary, to ensure successful completion within allocated budgets. 
Pollution Prevention (PP) Activities Estimated Percent Complete

\begin{tabular}{|c|c|c|c|c|}
\hline & & 25 & 50 & 75 \\
\hline 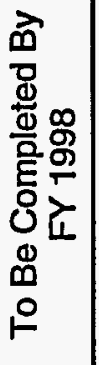 & $\begin{array}{l}\text { Establish Senior Management Commitment } \\
\text { Set Site Goals to Minimize Waste Generation } \\
\text { Institute PP Performance Measures } \\
\text { Perform PPOAs \& Implement Cost-Saving Projects } \\
\text { Design PP into New Products, Processes, and Facilities } \\
\text { Achieve Fully Compliant Site PP Programs }\end{array}$ & & & \\
\hline 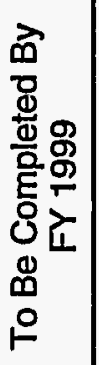 & $\begin{array}{l}\text { Implement Consistent Generator-Specific PP Programs } \\
\text { Reduce Releases of Toxic Chemicals } \\
\text { Establish PP Budgets Based on ADSs } \\
\text { Perform PP Cost-Benefit Analyses } \\
\text { Facilitate Technology Transfer \& Info. Exchange } \\
\text { Implement PP Employee Training \& Awareness Programs }\end{array}$ & & & \\
\hline 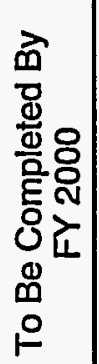 & $\begin{array}{l}\text { Implement Environmentally Sound PP Procurement Practices } \\
\text { Integrate PP into RDDT\&E Programs } \\
\text { Consistent Policies, Orders, \& Procedures } \\
\text { Implement PP Outreach \& Public Involvement } \\
\text { Develop PP Incentives Programs } \\
\text { Promote Regulatory Review and Reform }\end{array}$ & & & \\
\hline
\end{tabular}

$10 \%$ Complete Denotes a program that is fully developed as a policy concept, lead responsibilities are assigned, and implementation planning is under way.

$25 \%$ Complete Denotes a program that has completed all $H Q$ coordination and approval requirements, has secured resources, and is in initial deployment at DOE Operations Offices and/or Contractor sites.

$50 \%$ Complete Denotes an adequately funded program that has been institutionalized at all DOE Operations Offices and, with field oversight, is at the halfway point of complex-wide implementation.

$100 \%$ Complete Denotes a program that is fully institutionalized at all major contractor sites across the complex, and is operating as required by the Secretary's Quality Initiative.

Figure 3.4 Status and Priority of DOE Implementation of Pollution Prevention Activities 


\subsection{Sife Pollution Prevention Plans}

DOE Order 5400.1, "General Environmental Protection Program," requires Heads of Field Organizations to prepare plans for their pollution prevention awareness program activities. Such plans shall be reviewed annually and updated every 3 years. Plans were last submitted to Headquarters in 1994.

The guidance for preparation of the 1994 site plans, issued by the Deputy Secretary in March 1994, required the sites to set quantitative source reduction and recycling goals, estimate budgets for fiscal years 1994 through 2000, and address the key elements of the site-wide and generator-specific pollution prevention program (Appendix D, Figures D.3.1 and D.3.2). The resulting plans ranged from marginal to fully complete. In general, the larger sites had more complete plans and the smaller sites had fewer goals, budgets, and program elements.

Of greatest concern to Headquarters was the fact that when site waste reduction goals were summed across the complex, the resulting DOE-wide reductions between now and the end of 1999 were minimal, typically a few percent per year (or less) per waste type. The Secretary has set more aggressive, DOE-wide goals and requires Operations Office and site management to, as appropriate, update their plans, set stronger goals, and commit to achieve those goals. Operations Offices should review site plans for consistency with this plan and oversee required updates.

\subsection{Guidance on Funding Pollution Prevention}

The pollution prevention budget process is driven by the establishment of Secretarial goals and the specific priorities set forth in this document. To help achieve the goals and meet the priorities:

- Each individual site shall develop its own goals as required by DOE Order 5400.1 , designed to help achieve the DOE-wide goals, and should submit those goals and appropriate ADSs to its Operations Office for review and CSO approval.

- Operations Office management should prioritize pollution prevention ADSs submitted by the sites, and work with their Headquarters CSO counterparts to ensure that budgets are formulated to achieve the Secretarial goals.

- Headquarters CSOs that generate waste are encouraged to allocate dedicated funds to reduce priority pollutants and long-term waste costs (e.g. by funding return-on-investment projects). In addition, each waste-generating CSO should identify an annual pollution prevention budget associated with site resource requirements, and should exercise due diligence to budget for, and achieve, the goals set forth in this plan.

Federal managers should pay particular attention to the growing costs of DOE's environmental cleanup/ stabilization programs and to budget for cost-saving pollution prevention projects. Therefore, it is requested that all sites:

- Consider the entire life cycle of the cleanup process when considering pollution prevention actions.

- Plan for and implement pollution prevention in the cleanup process.

- Focus segregation, reuse, and recycling efforts on environmental restoration activities that will be generating low-level, hazardous, and lowlevel mixed wastes. 


\subsection{Pollution Prevention Roles and Responsibilities}

Overall responsibility for the development and execution of pollution prevention implementation rests with the CSOs, the Pollution Prevention

Executive Board, the Operations Office managers, and the heads of DOE laboratory and contracting organizations. Headquarters, Operations Office, and site management roles and responsibilities are summarized in Table 3.6 and explained more fully in Appendix E.

Table 3.6 Summary of DOE Roles and Responsibilities for Implementing Pollution Prevention

\begin{tabular}{|c|c|}
\hline Role & Responsibilities \\
\hline Secretan of En"ergy & $\begin{array}{l}\text { Sets Departmental pollution prevention goals and provides overall direction } \\
\text { to the Executive Board and the Cognizant Secretafial Offices. }\end{array}$ \\
\hline 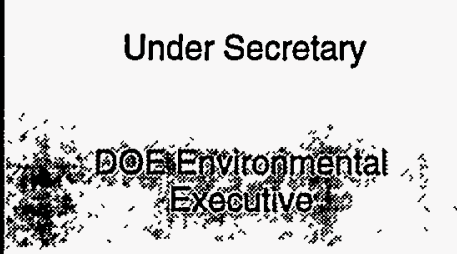 & $\begin{array}{l}\text { Provides senior management responsibility for coordination of the } \\
\text { Department's efforts in pollution prevention; chairs Executive Board. } \\
\text { Represents Department on Interagency Task Force for the implementation } \\
\text { of Exective Order (EO) } 12856 \text { and oversees the Department's progress in } \\
\text { Whilumenting EOs } 12856 \text { and } 12873 \text {. }\end{array}$ \\
\hline $\begin{array}{l}\text { Heads of Cognizant } \\
\text { Secretarial Offices }\end{array}$ & $\begin{array}{l}\text { Provide leadership, resources, and guidance in the development of site- } \\
\text { specific pollution prevention programs. }\end{array}$ \\
\hline 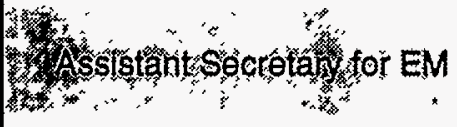 & $\begin{array}{l}\text { Provides overall coordination and assistance for the DOE-wide pollution } \\
\text { prevention effort, in addition to responsibilities as a CSO. }\end{array}$ \\
\hline Assistant Secretary for EH & $\begin{array}{l}\text { Ensures that DOE environmental policies and guidance facilitate } \\
\text { compliance with pollution prevention laws, regulations, and Executive } \\
\text { Orders. }\end{array}$ \\
\hline & 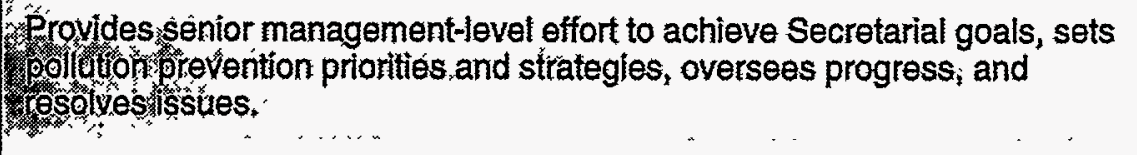 \\
\hline $\begin{array}{l}\text { Waste Reduction Steering } \\
\text { Committee }\end{array}$ & $\begin{array}{l}\text { Provides staff-level effort to coordinate implementation of this Program } \\
\text { Plan, assists the Executive Board, and facilitates technical information } \\
\text { exchange. }\end{array}$ \\
\hline Soge & 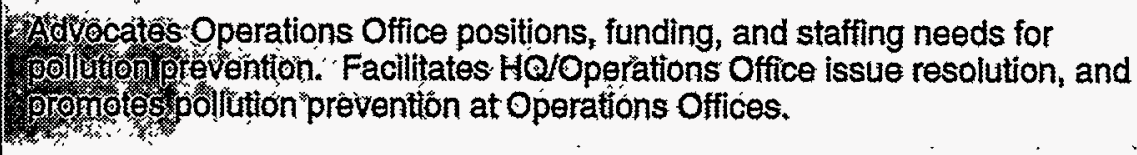 \\
\hline $\begin{array}{l}\text { Operations Office } \\
\text { Managers }\end{array}$ & $\begin{array}{l}\text { Implement DOE pollution prevention policies, review site-specific goals, } \\
\text { require that site plans comply with the requirements of this Program Plan, } \\
\text { measure site progress, and take corrective actions as necessary. }\end{array}$ \\
\hline 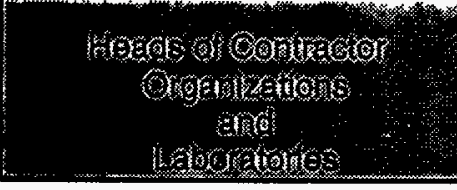 & 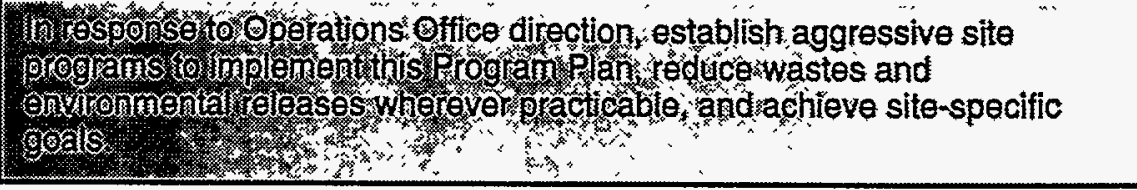 \\
\hline
\end{tabular}




\subsection{CONCLUSION}

This Program Plan establishes priorities and direction for DOE's pollution prevention program at Headquarters, the Operations Offices, and at the contractor and laboratory sites. It sets Secretarial waste reduction, recycling, and affirmative procurement goals to be achieved by December 31, 1999. It further advises Federal and contractor managers to budget for and aggressively implement 18 key pollution prevention activities, beginning in FY 1996 and concluding at the end of FY 1999. At that time, DOE's pollution prevention vision as expressed in Section 1.4 should be fully achieved across the complex.

The Department has committed to minimizing all types of wastes at their sources and preventing the release of pollutants to the environment as integral parts of DOE's overall efforts to improve environmental quality, conserve scarce resources, and reduce health risks to workers and to the public. 


\section{GLOSSARY OF TERMS}

Activity Data Sheets (ADSs) - Budget documents that contain the essential scope, schedule, cost, and management information, prepared by Operations Offices to provide input to the budgeting process. They are fundamental building blocks of the ES\&H Management Plan.

Affirmative Procurement Program - A program that ensures that items composed of recovered materials will be purchased to the maximum extent practicable, consistent with Federal law and procurement regulations (RCRA, Section 6002). Guidance on this program has been issued and is updated as EPA issues additional guidelines.

Annual Report on Waste Generation and Waste Minimization Progress - An annual report which chronicles ongoing Departmental waste generation activities and discusses waste minimization activities underway at DOE sites.

\section{Baseline Environmental Management Report} (BEMR) - Congressionally mandated report prepared by the Secretary of Energy to estimate the cost and schedule of cleaning up the Nation's nuclear weapons complex.

Byproduct - "Under the Resource Conservation and Recovery Act, a byproduct is a material that is not one of the primary products of a production process and is not solely or separately produced by the production process. Examples are process residues such as slags or distillation column bottoms. The term does not include a co-product that is produced for the general public's use that is ordinarily used in the form in which it is produced by the process."

Ile (2) Byproduct Material - "As defined by Section 11e (2) of the Atomic Energy Act of 1954, as amended, and Department of Energy Order
$5820.2 \mathrm{~A}, 11 \mathrm{e}(2)$ byproduct material is 'the tailings or waste produced by extraction or concentration of uranium or thorium from any ore processed primarily for its source material content.' Ore bodies depleted by uranium solution extraction operations and which remain underground do not constitute byproduct material."

Cleanup/Stabilization Waste - Cleanup/stabilization encompasses a complex range of activities including environmental restorátion of contaminated media (soil, groundwater, surface water, sediments, etc.); stabilization of nuclear and nonnuclear (chemical) materials; and deactivation and decommissioning (including decontamination) of facilities.

Cleanup/stabilization waste consists of one-time operations waste produced from environmental restoration program activities, including primary and secondary wastes associated with retrieval and remediation operations, "legacy wastes," and wastes from decontamination and decommissioning/transition operations. It also includes all TSCA regulated wastes, such as polychlorinated biphenylcontaminated fluids and/or equipment.

Note that cleanup/stabilization activities that generate wastes do not necessarily occur at a single point in time, but may have a duration of several years, during which time wastes are produced. By definition, these activities are not considered to be routine (periodic and/or on-going), because the waste is a direct result of past operations and activities, rather than a current process. Newly generated wastes that are produced during these "one-time operations" are considered to be a secondary waste stream, and are separately accounted for whenever possible. This secondary (newly generated) waste usually results from common activities such as handling, sampling, treatment, repackaging, shipping, etc. 
Cognizant Secretarial Office (CSO) - An office within the Department of Energy, headed by an Assistant Secretary or organizational Director, that reports to the Secretary and has management responsibility over designated multi-program Operations Offices and National Laboratories.

Decommissioning - Actions taken to reduce the potential health and safety impacts of contaminated DOE facilities, including activities to remove a facility from operation, followed by decontamination, entombment, dismantlement, or conversion to another use.

Direct Pollution Prevention Funding - Funding provided exclusively for pollution prevention activities.

Disposal - Emplacement of waste in a manner designed to isolate it from the biosphere, with no intention of retrieval for the foreseeable future, and that requires deliberate action to regain access to the waste.

DOE Orders - Internal requirements that establish DOE policy and procedures for compliance with applicable laws and regulations.

Environmental Restoration - Cleanup and restoration of sites contaminated with radioactive and/or hazardous substances during past production, accidental releases, or disposal activities.

Facility - Any building, structure, system, process, equipment, or activity that fulfills a specific purpose on a site.

\section{Generator-Specific Pollution Prevention Pro-} grams - Programs for identifying, evaluating, and implementing process and equipment modifications to achieve actual reductions in waste generation and pollutant release.
Hazardous Waste - The statutory definition found in section 1004(5) of RCRA (42 USCA 6903) is: a solid waste, or combination of wastes, that because of its quantity, concentration, or physical, chemical, or infectious characteristics, may (a) cause or significantly contribute to an increase in mortality or in serious irreversible, or incapacitating reversible illnesses, or (b) pose a substantial present or potential hazard to human health or the environment when improperly treated, stored, transported, or disposed of, or otherwise managed. Criteria for identification and listing of hazardous wastes are found in Title 40 of the Code of Federal Regulations, Part 261.

Infrastructure - The basic facilities, equipment, relationships, and frameworks needed for the functioning of a system or organization.

Legacy Waste - The backlog of stored waste remaining from the development and production of U.S. nuclear weapons, about which a permanent disposal determination remains to be made; i.e. waste that is currently in storage, retrievable storage on bermed pads, or buried in trenches.

Life Cycle - The stages of a product's, process's, or package's life, beginning with raw material acquisition, continuing through processing, materials manufacture, product fabrication, and use, and concluding with any variety of waste management options, including recycling.

Line Organization - An organizational chain of command which extends from an Assistant Secretary or organizational Director down through the staff levels of a Departmental organization (see also Cognizant Secretarial Office). 
Low-Level Radioactive Waste - Radioactive waste not classified as high-level waste, transuranic waste, spent nuclear fuel, or by-product material (specified as uranium or thorium tailings and waste in accordance with DOE Order 5820.2A).

Mixed Waste - Waste that contains both radioactive and hazardous components as defined by the Atomic Energy Act, TSCA, and RCRA. Mixed waste is further defined here as transuranic mixed, low-level mixed, and TSCA-regulated mixed.

Pollution Control - Measures that are applied after waste and pollutants are generated, such as: off-site recycling, waste treatment, concentrating hazardous or toxic constituents to reduce volume, diluting constituents to reduce hazard or toxicity, or transferring hazardous or toxic constituents from one environmental medium to another.

Pollution Prevention - The use of materials, processes, and practices that reduce or eliminate the generation and release of pollutants, contaminants, hazardous substances, and waste into land, water, and air. For DOE, this includes recycling activities.

Pollution Prevention Act of 1990 - Establishes source reduction as the strategy of first choice for waste management.

Pollution Prevention Executive Board - Established in 1992 to provide overall departmental leadership and direction for pollution prevention. Members include all CSOs. In 1996 the Under Secretary assumed the chairmanship.

Pollution Prevention Opportunity Assessment (PPOA) - Evaluation and appraisal of a process, activity, or operation as a way to identify potential waste minimization opportunities. Formerly called Process Waste Assessment.
Pollution Prevention Performance Measures Systems or techniques to measure pollution prevention progress by quantifying the amount of pollution not generated as a result of implementation of pollution prevention activities.

\section{Resource Conservation and Recovery Act} (RCRA) Regulated Waste - Solid waste, not specifically excluded from regulation under 40 CFR 261.4, or delisted by petition, that is either listed hazardous waste (40 CFR 261.30-261.33) or exhibits the characteristics of a hazardous waste.

Reclamation - The process of recovering a usable product from, or regenerating, materials that have been used at least once (e.g., recovery of lead from spent batteries, or regeneration of spent solvents).

Recycled - A material is recycled if it is reused or reclaimed (40 CFR 261.1 [7]).

Return-On-Investment (RO) Pollution Prevention Projects - Specific pollution prevention projects that rapidly pay for themselves (preferably. in 3 years or fewer) through reducing future pollutant generation.

Routine Operations Waste - Normal operations waste produced from any type of production, analytical, and/or research and development laboratory operations; treatment, storage, or disposal operations; "work-for-others;" or any periodic and recurring work that is considered ongoing. The term "normal operations" refers to the type of ongoing process (e.g., production) not the specific activity that produced the waste. Periodic laboratory or facility clean-outs and spill cleanups which occur as a result of these processes are also considered normal operations. 
Sanitary Waste - Wastes, such as garbage, that are generated by normal housekeeping activities and are not hazardous or radioactive.

Site - Land, installations, and/or facilities for which DOE has or shares responsibility for environmental restoration or waste management activities.

\section{Site-Wide Pollution Prevention Programs -} Broad pollution prevention activities that must be performed on a collective, site-wide basis. Includes implementing the policy of infrastructure activities and establishing site-wide source reduction and recycling programs and progress evaluation.

Small Site - One whose waste generation rates fall below the thresholds established by the Resource Conservation and Recovery Act (see Table 3.1).

Source Reduction - Any practice which reduces the amount of any hazardous substance, pollutant, or contaminant entering any waste stream or otherwise released into the environment (including fugitive emissions) prior to recycling, treatment or disposal; and any practice that reduces the hazards to public health and the environment associated with the release of such substances, pollutants, or contaminants.

Stabilization - Actions taken to further confine or reduce the hazards associated with contaminated sites, areas, buildings, or equipment.

State Regulated Waste - Any other hazardous waste not specifically regulated under RCRA, which may be regulated by State or local authorities, such as used oil.
Treatment - Any method, technique, or process (including neutralization) designed to change the physical, chemical, or biological character or composition of any hazardous, radioactive, or sanitary waste so as to neutralize such waste, to recover energy or material resources from the waste, or to render such waste nonhazardous; safer to transport, store, or dispose; or amenable for recovery or storage; or reduced in volume.

\section{Toxic Substances Control Act (TSCA) Regulated} Waste - Individual chemical wastes (both liquid and solid), such as polychlorinated biphenyls, that are regulated by the Toxic Substances Control Act.

Waste Generator - Individual, group, or organization at a facility that produces waste.

Waste Management - The systematic administration of the collection, storage, transportation, transfer, processing, treatment, and disposal of waste.

Waste Minimization - An action that economically avoids or reduces the generation of waste by source reduction, reducing the toxicity of hazardous waste, improving energy usage, or recycling. This action will be consistent with the general goal of minimizing present and future threats to human health, safety, and the environment.

Waste Reduction Steering Committee - Established in July 1988 to develop the DOE Headquarters pollution prevention program and provide guidance to sites. The Committee is composed of representatives from all DOE Headquarters offices. 


\section{ACRONYMS}

\begin{tabular}{|c|c|c|c|}
\hline ADSs & Activity Data Sheets & LLMW & low-level mixed waste \\
\hline \multirow[t]{2}{*}{ BEMR } & $\begin{array}{l}\text { Baseline Environmental Manage- } \\
\text { ment Report }\end{array}$ & LLW & low-level waste \\
\hline & & $\mathrm{m}^{3}$ & cubic meters \\
\hline $\mathrm{CSO}$ & Cognizant Secretarial Office & & \\
\hline CY & calendar year & MT & metric tons \\
\hline DOE & Department of Energy & PPOAs & $\begin{array}{l}\text { Pollution Prevention Opportunity } \\
\text { Assessments }\end{array}$ \\
\hline DP & Office of Defense Programs & RCRA & $\begin{array}{l}\text { Resource Conservation and Recovery } \\
\text { Act }\end{array}$ \\
\hline $\mathrm{EE}$ & $\begin{array}{l}\text { Office of Energy Efficiency and } \\
\text { Renewable Energy }\end{array}$ & RDDT\&E & $\begin{array}{l}\text { Research, Development, Demonstra- } \\
\text { tion, Test, and Evaluation }\end{array}$ \\
\hline EH & $\begin{array}{l}\text { Office of Environment, Safety and } \\
\text { Health }\end{array}$ & ROI & return on investment \\
\hline EM & $\begin{array}{l}\text { Office of Environmental } \\
\text { Management }\end{array}$ & TOXNET & $\begin{array}{l}\text { The National Library of Medicine's } \\
\text { on-line database that contains TRI } \\
\text { data. }\end{array}$ \\
\hline EPA & Environmental Protection Agency & & \\
\hline EPCRA & Emergency Planning and Community & & Toxic Chemical Release Inventory \\
\hline & Right-to-Know Act & TSCA & Toxic Substances Control Act \\
\hline ER & Office of Energy Research & WRSC & Waste Reduction Steering Committee \\
\hline $\mathrm{ES \& H}$ & environment, safety and health & & \\
\hline $\mathrm{FE}$ & Office of Fossil Energy & & \\
\hline FY & fiscal year & & \\
\hline
\end{tabular}




\section{APPENDIX A}

\section{Definition of Pollution Prevention}

Pollution prevention is defined as the use of materials, processes, and practices that reduce or eliminate the generation and release of pollutants, contaminants, hazardous substances, and wastes into land, water, and air. Pollution prevention includes practices that reduce the use of hazardous materials, energy, water, and other resources along with practices that protect natural resources through conservation or more efficient use. Within the Department, pollution prevention includes all aspects of source reduction as defined by EPA, and incorporates waste minimization by expanding beyond the EPA definition of pollution prevention to include recycling. Pollution prevention is achieved through:

- equipment or technology selection or modification, process or procedure modification, reformulation or redesign of products, substitution of raw materials, waste segregation, and improvements in housekeeping, maintenance, training, or inventory control;

- increased efficiency in the use of raw materials, energy, water, or other resources, including affirmative procurement; and

- recycling to reduce the amount of wastes and pollutants destined for release, treatment, storage, and disposal.

Pollution prevention can be applied to all DOE pollution-generating activities, including:

- manufacturing and production operations;

- facility operations, maintenance, and transportation;

- laboratory research;
- research, development, and demonstration;

- weapons dismantlement;

- stabilization, deactivation, and decommissioning; and

- legacy waste and contaminated site cleanup.

The Department is faced with the challenge of removing and treating wastes already generated from past production and manufacturing operations. Facility and equipment stabilization, deactivation and decommissioning, and weapons dismantlement activities will also result in significant amounts of wastes that must be handled. Many pollution prevention techniques may not directly apply to wastes that were generated and media that were contaminated by previous practices (nonroutine wastes). However, two techniques, waste segregation and recycling, will be key to reducing the amount of such wastes that would otherwise require additional treatment and disposal.

Additional waste and pollutants will be generated in the process of conducting restoration and dismantlement activities. Pollution prevention is applicable to the generation of secondary wastes and will be incorporated into remedial investigations, feasibility studies, design, and execution of all restoration and dismantlement projects. Restoration projects will be performed in a manner that reduces or prevents the generation of new waste and pollutants, and reduces the further release or spread of contamination. 


\title{
APPENDIX B
}

\author{
United States Department of Energy Pollution Prevention Strategy \\ Issued by Secretary O'Leary to all Department Elements on December 27, 1994
}

\section{POLICY STATEMENT:}

"The Department of Energy (DOE) embraces pollution prevention as its strategy to reduce the generation of all waste streams and thus minimize the impact of departmental operations on the environment, as well as improving safety of operations and energy efficiencies. I expect the Department to continue the leadership shown by our voluntary compliance with the Emergency Planning and Community Right-to-Know Act (EPCRA) and our participation in the Environmental Protection Agency's 33/50 program which focuses on near-term pollution prevention efforts of 17 priority toxic chemicals.

...Recognizing that pollution prevention is the Department's preferred approach to meeting its environmental responsibilities, I am directing that Cognizant Secretarial Offices, working in conjunction with the Pollution Prevention Executive Board, identify, plan, and allocate funds for field implementation of waste minimization and pollution prevention activities during the departmental budget review process. This information will be used to provide an identified budget each year dedicated to pollution prevention activities."

Secretary Hazel R. O'Leary, December 28, 1993

\section{RESPONSIBLE INDIVIDUAL:}

DOE is committed to ensuring the success of its pollution prevention goals. Because of this commitment, the Department has designated the Deputy Secretary of Energy as the senior manager responsible for coordination of the Department's efforts in pollution prevention. The Deputy Secretary may designate another individual to act on his behalf should the need arise.

\section{BACKGROUND:}

The Department of Energy has had a long-standing commitment to implementing the principles contained in Executive Order 12856, "Federal Compliance with Right-to-Know Laws and Pollution Prevention Requirements." DOE facilities have been active in complying with EPCRA since its passage in 1986. The Department has provided guidance and training materials on the general requirements of EPCRA, and specific guidance and training on Toxics Release Inventory (TRI) reporting. In fact, the Department has led the Federal sector in TRI reporting by voluntarily committing to report TRI releases prior to the issuance of the Executive Order, and has worked closely with EPA during 1992 and 1993 on resolving issues of Federal facility TRI reporting.

The Department has also been a leader in the development and implementation of pollution prevention programs and activities, including voluntary participation in EPA's $33 / 50$ program. In 1988, 12 DOE facilities filed Form $R$ reports with EPA as sites which used or stored chemicals to be reported under TRI. Since then, DOE facilities have met, ahead of schedule, the Department's goal of a 50 percent reduction in TRI releases and transfers of the seventeen priority toxic chemicals covered by the EPA $33 / 50$ program. In addition, facility-specific pollution prevention plans are required under DOE Order 5400.1, General Environmental Protection Program, and the Department has issued guidance to its facilities on the preparation of those plans. DOE has actively involved nearly all Departmental organizations in pollution prevention activities at the staff level through the Waste Reduction Steering Committee, and at the senior management level through the Pollution Prevention Executive Board, chaired by the Deputy Secretary of Energy. 
The combined effort of these groups produced the Department's 1994 Waste Minimization/Pollution Prevention Program Plan, as well as a program to identify and implement pollution prevention projects which can produce successful results in the near-term. In addition, the Department has established a pollution prevention funding mechanism through the Department-wide Environment, Safety and Health Management Plan. This will ensure that pollution prevention programs are funded that reduce toxic emissions and waste generation in a cost effective manner.

Every effort has been, and will continue to be, made to involve the public and other stakeholders in monitoring the Department's progress in meeting the requirements of Executive Order 12856.

The attached bibliography details past Departmental efforts to implement pollution prevention through Secretarial memoranda, guidance documents, and planning documents. The objectives and goals which follow build upon the previous efforts and upon the Department's other pollution prevention successes to date.

\section{OBJECIIVE 1: EFFECTIVELY INSTITUTIONALIZE THE POLLUTION PREVENTION ETHIC THROUGH TRAINING AND AWARE- NESS IN ALL MISSION AREAS}

\section{DOE OFFICES OF RESPONSIBILITY: All Cognizant Secretarial Offices}

\section{Sub-objective 1.1}

Develop an environmentally aware DOE community through education and training in pollution prevention so that all personnel understand the DOE commitment to utilize pollution prevention through source reduction, where practicable, as the primary means of achieving and maintaining compliance with all applicable Federal, State, and local environmental regulations.
- Equip our work force with the pollution prevention skills to accomplish DOE's missions while protecting the environment.

- Institutionalize and continually improve appropriate pollution prevention training for our personnel.

- Integrate pollution prevention measures into all operations.

\section{Sub-objective 1.2}

Promote pollution prevention through multimedia outreach/awareness programs and partnerships.

- Strengthen working relationships with regulators at all levels.

- Foster partnerships with stakeholders and industry by:

- participating in local community emergency planning;

- enhancing the coordination and effectiveness of local emergency response capabilities;

- providing communities with information on toxic chemical use and release by reporting under TRI;

- promoting the elimination of the use of hazardous substances, a reduction in toxic emissions, and a reduction in the generation of hazardous waste and DOE facilities; and 
- encouraging affirmative procurement of non hazardous chemicals and materials and products with recycled content, and the reuse and recycling of materials when possible.

- Demonstrate innovative leadership in and commitment to pollution prevention.

- Disseminate information on pollution prevention technologies throughout the DOE complex.

- Work with other Federal agencies on information exchange.

\section{Sub-objective 1.3}

Encourage and recognize outstanding pollution prevention efforts through existing and new awards/incentive programs.

\section{OBJECTIVE 2: REDUCE RELEASES AND OFF-SITE TRANSFERS OF TOXIC CHEMICALS TO THE ENVIRONMENT}

\section{DOE OFFICES OF RESPONSIBILITY: All Cognizant Secrefarial Offices}

\section{Sub-objective 2.1}

Minimize releases of toxic chemicals to the environment and off-site transfers of such toxic chemicals. To the maximum extent possible, such reductions shall be achieved through source reduction.

\section{GOAL:}

By December 31, 1999, achieve a Department-wide 50 percent reduction of total releases of toxic chemicals to the environment and off-site transfers of such toxic chemicals from the baseline year
(DOE will determine the baseline year after further study).

\section{Sub-objective 2.2}

Establish site-specific goals to reduce the generation and use of radioactive and other hazardous materials to the extent practicable.

\section{Sub-objective 2.3}

Develop, maintain, and implement pollution prevention plans at each major facility. These plans may include baselines, pollution prevention opportunity assessments, and investment strategies.

\section{Sub-objective 2.4}

Implement cost-effective pollution prevention at all DOE facilities.

\section{Sub-objective 2.5}

Submit annual reports to the EPA Administrator regarding progress made toward achievement of the above goal, as well as progress made in complying with all other aspects of Executive Order 12856.

\section{OBJECTIVE 3: INCORPORATE POLLUTION PRE- VENTION POLICY INTO THE ACQUI- SITION PROCESS}

\section{DOE OFFICES OF RESPONSIBILITY: All Cognizan\} Secretarial Offices}

\section{Sub-objective 3.1}

Integrate environmental considerations into acquisition strategies, plans, and the source selection process. Employ life cycle analyses and total cost accounting principles in procurements, as appropriate. 


\section{GOALS:}

1. Establish a Department-wide plan, with goals, to eliminate or reduce unnecessary acquisitions of hazardous substances or toxic chemicals.

2 Establish a Department-wide plan, with goals, to reduce DOE manufacture, process, and use of extremely hazardous substances and toxic chemicals.

\section{Sub-objective 3.2}

Integrate pollution prevention considerations when developing mission needs and when developing and revising acquisition documentation.

\section{GOAL:}

By August 3, 1995, review DOE standards and specifications to identify opportunities to eliminate or reduce unnecessary acquisitions of hazardous or toxic substances, and complete all necessary revisions by December 31, 1998.

\section{OBJECTIVE 4: ACHIEVE EMERGENCY PLANNING AND COMMUNITY RIGHT-TO- KNOW REPORTING}

\section{DOE OFFICES OF RESPONSIBILITY: All Cognizant Secretarial Offices}

\section{Sub-objective 4.1}

Develop and maintain a comprehensive inventory of toxic chemicals, extremely hazardous substances, and hazardous chemicals at each DOE facility.

\section{Sub-objective 4.2}

Ensure that each facility fulfills all EPCRA reporting responsibilities, including:
- Emergency planning notification.

- All other information needed for local emergency planning.

- Chemical inventory information to local emergency planning committees.

- Emergency notification to local emergency response teams.

- TRI reporting.

\section{OBJECTIVE 5: ADDRESS OTHER ENVIRONMENTAL QUALITY ISSUES AND POLLUTION PREVENTION FOCUS AREAS}

\section{Sub-objective 5.1}

Address the requirements of Executive Order 12898, "Federal Actions to Address Environmental Justice in Minority Populations and Low-Income Populations," signed by the President on February 11, 1994. This Executive Order focuses on achieving environmental justice by promoting nondiscrimination in DOE's programs that affect human health and the environment.

\section{Sub-objective 5.2}

Promote water conservation, energy efficiency, and use of renewable energy technologies, as required by Executive Order 12902, "Energy Efficiency and Water Conservation at Federal Facilities."

- Minimize life cycle costs by utilizing energy efficiency, water conservation, and renewable energy resources in the design and construction of new facilities, as well as in the modification of existing facilities. 


\section{GOALS:}

1. By December 31, 2004, achieve a 30 percent Department-wide reduction in energy consumption from the 1985 baseline.

2. By December 31, 2004, increase Departmentwide energy efficiency by at least 20 percent from the 1990 baseline.

\section{Sub-objective 5.3}

Optimize the use of environmentally preferable materials in the planning, construction, and maintenance of facilities. Establish and promote efficient material/energy-use practices through conservation, reutilization, materials substitution, recycling, affirmative procurement, and the creation of markets for recycled materials, as required by Executive Order 12873, "Federal Acquisition, Recycling, and Waste Prevention."

\section{Sub-objective 5.4}

Incorporate pollution prevention principles, techniques, and mechanisms into all planning and decision making processes. Evaluate and report those efforts in documentation required by the National Environmental Policy Act.

\section{OBJECTIVE 6: DEVELOP, TRANSITION, AND APPLY INNOVATIVE POLLUTION PREVEN- TION TECHNOLOGIES}

\section{DOE OFFICES OF RESPONSIBILITY: All Cognizant Secrefarial Offices}

\section{Sub-objective 6.1}

Develop and support a DOE Strategic Plan to identify and prioritize research, development, demonstration, testing, and evaluation (RDDT\&E) needs.
- Focus pollution prevention RDDT\&E on developing and implementing critical technologies needed for source reduction.

- Encourage user participation in formulating requirements.

\section{Sub-objective 6.2}

Identify and fund high priority RDDT\&E programs.

- Identify, develop, and implement a RDDT\&E plan.

\section{Sub-objective 6.3}

Coordinate DOE's pollution prevention RDDT\&E programs with those of other Federal agencies, academia, and private industry.

- Identify material and process substitutes in DOE technologies that have government-wide as well as commercial application for expedited implementation.

- Foster cooperative interagency, Federal-State, and government- industry partnerships to solve pollution prevention issues.

- Actively demonstrate and implement "off-theshelf" technologies that ensure the mission capability of DOE facilities.

- Integrate pollution prevention measures into all appropriate operations.

\section{Sub-objective 6.4}

Encourage the development of strong domestic and foreign markets for DOE-developed, innovative pollution prevention technologies. 
- Develop, demonstrate, test, evaluate, and implement innovative pollution prevention technologies at DOE facilities.

- Forge partnerships with environmental technology firms abroad to export DOE-developed pollution prevention technologies.

\section{BIBLIOGRAPHY}

Office of Environmental Guidance, RCRA/ CERCLA Division (EH-231) Memorandum, December 13, 1989, subject: "Compliance with the Requirements of the Superfund Amendments and Reauthorization Act (SARA) Title III."

Office of Environmental Guidance, RCRA/ CERCLA Division (EH-231), Emergency Planning and Community Right-to-Know Act (EPCRA), DOE/EH-0181P, March 1991.

Secretarial Memorandum, September 22, 1992, subject: "Department of Energy Participation in the 33/50 Pollution Prevention Program and Voluntary DOE Toxic Chemical Release Inventory Reporting."

Office of Environmental Guidance, RCRA/ CERCLA Division (EH-231), Toxic Chemical Release Inventory and 33/50 Pollution Prevention Program, DOE/EH-0305, March 1993.
Office of Environmental Guidance, RCRA/ CERCLA Division (EH-231), Emergency Planning and Community Right-to-Know Act (EPCRA) Requirements, DOE/EH-231-018/1093, October 1993.

Office of Environmental Guidance, RCRA/ CERCLA Division (EH-231), Department of Energy Toxic Chemical Release Inventory Reporting "Qs \& As," DOE/EH-0374, March 1994.

Office of Environmental Guidance, RCRA/ CERCLA Division (EH-231) Memorandum, April 7, 1994, subject: "Toxic Chemical Release Inventory (TRI) Reporting - Guidance Update."

Office of Environmental Guidance, RCRA/ CERCLA Division (EH-231), Hazardous Substance Release Reporting under CERCLA, EPCRA Section 304, and DOE Emergency Management System/Occurrence Reporting Requirements, DOE/ EH-0383, June 1994.

Office of the Secretary, Waste Minimization/ Pollution Prevention Program Plan 1994, DOE/FM0145, February 1994. 


\section{APPENDIX C}

\section{Summary of Special Issue Review of Pollution Prevention Management Findings}

1. Awareness and Understanding of Pollution Prevention
Although the 1994 Crosscut Plan clearly delineates DOE's pollution prevention pro- gram, awareness and acceptance of pollution prevention throughout the Department remains low. More effort needs to be made to promote a greater understanding among management and staff of the nature of pollution prevention and the benefits it can provide.

\section{Management Commitment}

While top management has outwardly expressed its support for pollution prevention, it needs to establish clear expectations, support efforts toward meeting those expectations by allocating resources, and ensure progress through systems of accountability. Middle management needs to follow this direction in its respective organizations, which includes allocating sufficient resources to support pollution prevention projects, establishing incentives and rewards, and ensuring progress.

3. Organizational Issues

The current organizational structure and the corresponding roles and responsibilities associated with the pollution prevention program have resulted in fragmentation of the program. Organizational issues present three major challenges for the pollution prevention program: 1) finding ways to coordinate the numerous programs and activities that contribute to the Department's overall pollution prevention goals; 2) bridging the gap between the Waste Minimization Division's program development efforts and line program implementation; and 3) strengthening linkages and coordination between Headquarters, operations offices, and field sites.

4. Financial Incentives and Disincentives

Because generators are not responsible for waste disposal costs and savings from pollution prevention activities do not necessarily accrue to them, few financial incentives currently exist to promote pollution prevention. Creating more financial incentives for generators to implement pollution prevention programs should increase the pace of pollution prevention activities across the DOE complex.

5. Pollution Prevention Funding Prioritization

Currently, there is no established methodology for prioritizing or selecting pollution prevention projects that crosscut DOE at an agency-wide, or site-wide level. The project ranking and prioritization schemes that do exist for allocation of funds to operating and capital projects focus primarily on reducing near-term risk rather than long-term benefit.

6. Integration Into Environmental Restoration, and Decontamination and Decommissioning

Pollution prevention is not well integrated into environmental restoration strategies and practices, either broadly or 'within each project. Over the 'next decade and perhaps beyond, the amount of waste produced by DOE from environmental restoration and decontamination and decommissioning activities will continue to 
rise at a substantial rate and will ultimately represent the vast majority of the wastes produced by the sites (Figure 2.2). Consequently, it is essential that DOE integrate pollution prevention within all phases of environmental restoration and decontamination and decommissioning.

\section{Technical Assistance}

More specific technical assistance that focuses on methodologies, tools, and techniques for pollution prevention implementation will complement DOE's existing policies to improve the effectiveness of the overall pollution prevention program.

8. Moratorium on Offsite Shipment of Waste

The current moratorium on the offsite shipment of wastes that may be radioactive has affected not only offsite treatment and disposition of wastes, but also efforts to recycle salvageable equipment, industrial and sanitary wastes, reusable materials, and excess supplies at a number of sites. Additional support and guidance may be necessary to advance pollution prevention programs at these sites in the near term.

\section{Changing Mission}

DOE's mission with respect to its national defense operations has been changing rapidly. Uncertainty associated with the future mission of many DOE sites and operations has led to hesitation not only in fully accepting the importance of pollution prevention, but also in committing resources for projects associated with processes that could change significantly or be discontinued.

A complete copy of the Special Issue Review can be obtained through the DOE Office of Environmental Audit, Office of Environment, Safety \& Health (DOE/EH-0421). 


\section{APPENDIX D}

\section{Pollution Prevention Activity Plan}

Implementation of the pollution prevention activities described below is essential to meeting goals for reducing waste generation.

\section{D.1 Pollution Prevention Policy Direction Activities}

\section{D.1.1 Establish Goals to Minimize Waste Generation and Environmental Releases}

Goal-setting is a fundamental requirement in any performance-based management system and is essential if DOE is to achieve significant reductions in waste generation and environmental releases. DOE managers can more effectively plan, organize, budget for, and execute programs to achieve actual reductions in waste generation when goals are set.

Goal-setting provides targets for reducing waste generation, standards for evaluating pollution prevention progress, and a framework for decision making. Accordingly, each DOE site will set quantitative pollution prevention goals and develop plans for achieving those goals. These goals will be compatible with the overall agency goals described in Section 3.2.2 of this plan.

\section{D.1.2 Establish Senior Management Commitment and Follow-Through for DOE Pollution Prevention Activities}

A successful DOE-wide pollution prevention program depends upon proactive leadership and hands-on management by DOE and contractor senior managers. All DOE Headquarters organizations, Operations Offices, DOE facilities, laboratories, and contractor organizations must exhibit commitment to pollution prevention. The heads of these organizations will translate the Secretarial pollution prevention policy into policies specific to their sites or programs and will be accountable for incorporating them into routine operations.

\section{D.1.3 Distinguish Pollution Prevention Budget Allocotions through Activity Data Sheets}

Sufficient funding is an essential aspect of managing programs, measuring organizational commitment, and performing cost/benefit analyses. Currently, the Department is inconsistently funding pollution prevention through overhead accounts, programmatic accounts, and special project accounts. Expenditure levels for establishing and implementing site programs often are not known.

The Department must be able to distinguish pollution prevention funding from other programs and operations. Therefore, specific budgets will be established through preparation of separate Activity Data Sheets for pollution prevention activities. These Activity Data Sheets will be included in and tracked by the ES\&H Management Plan to evaluate investment in pollution prevention across the Department.

\section{D.1.4 Promote Regulatory Review and Provide Technical Assistance}

Federal and State environmental regulations and standards provide significant benefits to the public, but can sometimes hinder pollution prevention initiatives. For example, due to the lack of a "de minimis" criterion, DOE often classifies much of its municipal waste as radioactive and much of its hazardous waste as mixed. This results in the need for expensive treatment and disposal for wastes that could otherwise be recycled, reused, or handled by commercial treatment and disposal facilities. 
Risks associated with hazardous and radioactive waste need to be evaluated considering the latest scientific evidence. The Department will seek opportunities to provide technical assistance to those formulating Federal and State environmental regulations. The Department will seek to promote cost-effective pollution prevention actions as opposed to expensive waste treatment, storage, and disposal practices.

\section{D.1.5 Consistent DOE Policies and Procedures to Integrafo Pollution Prevention}

Various DOE guidance documents and directives may inadvertently create barriers to pollution prevention. Examples of these include security issues with recycling, the inability to substitute materials due to restrictive standard operating procedures, and a focus on pollution control versus pollution prevention. Applicable DOE policies and Orders must be updated to outline pollution prevention roles and responsibilities, develop consistent procedures, and create an environment to resolve internal conflicts over such matters. Therefore, DOE policies and procedures will be updated to reflect the Department's and the Administration's focus on integrating pollution prevention objectives into all activities.

\section{D.2 Pollution Prevention Infrastructure Development}

\section{D.2.1 Establish Clear and Accountable Performance Measures}

Performance measures can be established when standardized material and waste tracking systems are developed. Quantitative measurements of DOE's pollution prevention progress are difficult because of the variety of waste generating activities, such as production, laboratory experimentation, and environmental restoration. DOE currently lacks the ability to fully track across multiple sites the amounts of waste generated and pollutants released as a result of its activities. Required data often are gathered manually through time consuming and expensive "data calls" to the field. Definition and interpretation issues often restrict the value of the final roll-up information. Performance measures for pollution prevention must be developed and applied consistently throughout all DOE organizations for the data to be valid and useful for the complex. To assist in this task, the Department will develop standards and criteria to measure materials and wastes and provide performance requirements for material and waste tracking systems. This will provide DOE managers with the information needed to establish meaningful goals for reducing waste generation and environmental releases, evaluate progress, and evaluate compliance with regulatory and Departmental drivers.

\section{D.2.2 Analyze Pollution Prevention Costs and Benefits for Use In Decision Making}

Currently, DOE does not know the full costs (direct plus hidden costs) of managing the Department's many individual waste streams and emissions, and associated loss of production efficiency due to excess energy and material usage. Material and waste management costs, including those paid by generators, must be estimated if DOE decision makers are to properly balance the benefits of applying pollution prevention versus the costs to continue operations without process improvements. DOE decisions on how best to manage existing and future waste streams must be made with a full understanding of future cost liability if DOE is to minimize the total cost to the taxpayers.

The Department will develop standards for estimating the costs and benefits of introducing pollution prevention into its operations. Economic analyses will provide a more thorough picture of waste generation versus costs of implementing pollution prevention for more informed Departmental decision making. 


\section{D.2.3 Facilitate Pollution Prevention Technology Transfer and Information Exchange}

Effective technology transfer and information exchange provides updated information to each DOE site on pollution prevention opportunities and efficient methods for implementation. This leverages Departmental resources by providing more comprehensive knowledge of pollution prevention opportunities, reduces duplication of effort, and allows sites to benefit from lessons learned at other sites. A model site program will be developed to demonstrate outstanding environmental management performance within the Department to enhance and expedite pollution prevention technology transfer and information exchange. The Department will enhance existing systems to optimize technology transfer and information exchange within the DOE complex to provide consistent application of pollution prevention opportunities. The Department will also cooperate with other Federal, State, and local agencies, and industry to share pollution prevention technologies and information.

\section{D.2.4 Develop a DOE Pollution Prevention Incen- tives Program}

Incentives are necessary to stimulate and maintain interest in changing processes and activities. Providing budgetary incentives within the Department is difficult because waste management is funded by the EM organization as a service to all other waste generating organizations. Consequently, waste generators are not directly charged for waste management costs, nor do they financially benefit from reducing waste generation and environmental release rates. Without incentives, beneficial changes in generator facilities might not be made if there are no immediate avoided costs to the generator. To help remedy that situation, the Department will acknowledge and reward reductions in waste generation and environmen- tal releases made by the responsible line organizations.

\section{D.2.5 Develop and Conduct Pollution Prevention Employee Training and Awareness Programs}

Employee pollution prevention training is integral to increasing awareness of environmental issues and the positive effects each employee can have on the environment. DOE has found it particularly difficult to reach and educate all DOE and contractor employees who generate hazardous, radioactive, mixed, and or municipal waste in their day-to-day activities. Adoption of pollution prevention practices by all management levels and the work force requires effective training programs that articulate program requirements and benefits.

The goal is to make each DOE and contractor employee aware of waste generation, its impact on the site and the environment, and ways resources may be conserved and waste generation and environmental releases reduced. The Department will operate a comprehensive pollution prevention training program that considers all applicable job-specific situations to achieve this goal.

\section{D.2.6 Develop and Implement a Pollution Prevention Outreach and Public Involvement Program}

The public understands that effective application of pollution prevention promotes health, safety, and environmental quality. Keeping stakeholders informed of DOE's progress will build public confidence and institutional credibility. The Department will involve stakeholders and local communities in pollution prevention programs and invite them to participate in emergent environmental activities and initiatives. DOE must have a visible and active program if it wishes to convince the public that it will protect future generations as it cleans up the waste of the past 
and responsibly manages new waste-generating activities.

\section{D.3 Pollution Prevention Program Implementation}

\section{D.3.1 Develop and Maintain Site Pollution Preven- tion Programs that Comply with Federal, State, and Departmental Directives}

Certain site activities must be performed at all sites regardless of the pollutant or waste types generated or the number of generator organizations. Such activities include site-wide coordination, planning, reporting, training, employee awareness, assessments, and recycling and affirmative procurement programs. The Department will develop core pollution prevention activities and services at every site. Figure D.3.1 contains the key elements of a site-wide program. These elements and subelements may be considered tasks and sub-tasks of a site-wide program.

Currently, DOE's site-wide pollution prevention programs are constrained due to uncertainty over which DOE line organization (EM, the landlord, waste generator) is responsible for funding and managing these activities. DOE will clarify its organizational roles and responsibilities to ensure stable funding and consistent management of site pollution prevention programs that comply with applicable Federal, State, and Departmental directives.

\section{D.3.2 Develop and Maintain Consistent Generator-Specific Programs}

Waste generator organizations must implement essential process, material, and capital equipment changes and waste avoidance techniques within operating facilities to achieve real and substantial reductions in DOE's waste generation rates. Senior management leadership is particularly needed today to accomplish this mission within the Department. Generators must perform opportunity assessments to identify pollution prevention opportunities. Generators must also plan and budget for cost-effective changes in their operations and include pollution prevention programs within their multi-year program plans.

Key elements of a generator-specific program include program management and coordination, planning and training, performance of opportunity assessments, implementation of pollution prevention techniques, goal-setting and tracking, and program progress evaluation. The Department will require waste generating organizations to include appropriate pollution prevention concepts and techniques in their program operations and other activities such as weapons disassembly, stabilization, deactivation, and environmental restoration. Figure D.3.2 contains the key elements of a generator-specific program. These elements and sub-elements may be considered tasks and sub-tasks of a generator-specific program.

\section{D.3.3 Perform Opportunity Assessments and Implement Pollution Prevention Projects}

In addition to meeting its immediate environmental regulatory requirements, the Department has a responsibility to the public to reduce future pollution associated with waste generated today. Opportunity assessments provide the first.step in identifying cost-effective techniques to reduce waste generation and pollutants. An opportunity assessment involves an in-depth examination of processes, operations, and procedures and assists in identifying pollution prevention projects that will yield a quick return on investment. The Department, acting to minimize total costs, will perform opportunity assessments and identify and implement projects that show a rapid (within 36 months) return on investment. 


\section{Site Pollution Prevention Program}

\begin{tabular}{|c|c|}
\hline & PP Coordinator \\
\hline \multirow{7}{*}{ Organization and Infrastructure } & HO/Operations Office Interface \\
\hline & - Integrate/Monitor Generator Program \\
\hline & - Participate in DOE Program \\
\hline & 4 PP Coordinator Network \\
\hline & PP Site Plan \\
\hline & PP Site Policy \\
\hline & Objectives and Goals \\
\hline \multirow{7}{*}{ Program Development } & Activity Schedule \\
\hline & Affirmative Procurement \\
\hline & Personnel \\
\hline & Operating Procedures \\
\hline & Quality Assurance \\
\hline & General Employee Training \\
\hline & Awareness \\
\hline \multirow[t]{2}{*}{ Employee Involvement } & $-\overline{\text { Awards and Recognition }}$ \\
\hline & \begin{tabular}{|l} 
Employee Evaluation \\
Newsletters
\end{tabular} \\
\hline & Material Inventory \\
\hline \multirow[t]{2}{*}{ Tracking } & Waste Tracking \\
\hline & Compliance Reporting \\
\hline \multirow[t]{4}{*}{ Reporting } & Reports to HO \\
\hline & Heports to Operations Ofilice \\
\hline & Toxics Reduction \\
\hline & Material Substitution \\
\hline \multirow[t]{3}{*}{ Site-wide Waste Reduction } & Material Exchange \\
\hline & \\
\hline & Goal Setting \\
\hline \multirow{3}{*}{ Technical Assistance } & Baseline Determination \\
\hline & Model Programs \\
\hline & Seminars, Workshops, Meetings \\
\hline \multirow{3}{*}{ Information and Technology Exchange } & PP Coordinator Meetings \\
\hline & Outreach and Public Relations \\
\hline & Employee Participalion \\
\hline Program Evaluation & Waste Reduction Periormance \\
\hline
\end{tabular}

Figure D.3.1 Key Elements of a Compliant Site Pollution Prevention Program 
Generator-Specific Pollution Prevention Program

Organization and Infrastructure

\begin{tabular}{|c|c|}
\hline \multirow{3}{*}{ Facility Training } & Job-specific \\
\hline & Opportunity Implementation \\
\hline & Evaluate Waste Generating Activities \\
\hline \multirow[t]{4}{*}{ Opportunity Assessments } & Identify and Prioritize Opportunities \\
\hline & Identify R\&D Needs \\
\hline & Process Modifications \\
\hline & Materia! Substitutions \\
\hline \multirow[t]{2}{*}{ Opportunity Implementation } & Capital Expenditures \\
\hline & R\&D and Demonstration \\
\hline
\end{tabular}

Design Considerations

Program Evaluation 1 Program Implementation

Figure D.3.2 Key Elements of a Generator Specific Pollution Prevention Program 


\section{D.3.4 Design Pollution Prevention into New Products, Processes, and Facilities}

Engineering design is a critical component of DOE's products, processes, and facilities. It is estimated that 70 percent or more of the opportunity to reduce or eliminate pollutants exists during design. Designing pollution prevention into new DOE products, processes, and facilities prevents or greatly reduces environmental releases, promotes efficient energy and materials use, and leads to lowest agency life-cycle costs. This effort is also known as "Design for the Environment."

The Department will integrate Pollution Prevention into all new design criteria. Resource efficiency will be considered a priority in all new designs or redesigns for products, processes, and facilities. Pollution prevention considerations will be included in preparation of environmental assessments and environmental impact statements under NEPA.

\section{D.3.5 Infegrate Pollution Prevention into Re- search, Development, Demonstration, Test, and Evaluation Projects}

The Department faces significant technical hurdles, particularly for its mixed and radioactive waste streams, that will continue to impede waste management progress and increase costs until satisfactory technical solutions are developed. Applying pollution prevention research, development, demonstration, test, and evaluation (RDDT\&E) solutions to critical areas of need is essential because of the size and technical challenges of the Department's waste management program. The Department will integrate waste generation and RDDT\&E to ensure that pollution prevention RDDT\&E projects offering the greatest technical benefit are available to generator organizations.

\section{D.3.6 Modify Procurement Practices to Promote Pollution Prevention}

As a significant purchaser of materials and equipment, the Department will promote the purchase of less toxic, more durable, more energy efficient materials, including products composed of recovered materials, for its own operations. The Department will ensure the use of environmentally sound practices in the procurement process including updating user specifications, contracts, and policies. This will ensure that DOE and its contractors act according to existing Federal, State and local regulations, and DOE Orders and policies. Special priority within this activity will be given to meeting the requirements of Executive Order 12856, "Federal Compliance with Right-to-Know Laws and Pollution Prevention Requirements," Executive Order 12843, "Procurement Requirements and Policies for Ozone-Depleting Substances," and Executive Order 12873, "Federal Acquisition, Recycling, and Waste Prevention."

\section{D.3.7 Reduce Releases of Toxic Chemicals}

The Department will reduce the releases and offsite transfers of TRI chemicals 50 percent by December 31, 1999. All sites that meet the EPCRA toxic chemical use reporting thresholds will submit to EPA TRI Form Rs on each applicable chemical. Sites that did not submit TRI Reports in the past due to their Standard Industry Classification Code status began reporting with 1993 data. Each site will participate in reducing TRI chemical releases to ensure Departmental compliance with Executive Order 12856. The baseline year for measuring DOE-wide reductions under the Executive Order is 1993. 


\section{APPENDIXE}

\section{Roles and Responsibilities}

\section{E.1 Secretary of Energy}

The Secretary of Energy sets the goals and provides the vision, programmatic leadership, and management direction for pollution prevention crosscutting activities. In addition, the Secretary approves the charter of, and provides overall direction to, the Pollution Prevention Executive Board.

\section{E.2 Under Secretary of Energy}

The Under Secretary of Energy has senior management responsibility for coordinating the Department's efforts in pollution prevention. Responsibilities include chairing the Pollution Prevention Executive Board meetings and convening the Board quarterly.

\section{E.3 DOE Environmental Executive}

The DOE Environmental Executive, as designated by the Secretary and defined in E.O. 12873, is responsible for:

- coordinating the implementation of Executive Orders 12856 and 12873 throughout the Department;

- participating in the interagency development of a Federal plan to create internal and external awareness and outreach programs, promote new technologies, establish incentives, provide guidance and coordinate employee education programs and coordinate the development of standardized agency reports;

- reviewing agency programs and acquisitions to ensure compliance with E.O. 12873;

- tracking the Department's purchases of EPA guideline items and submitting required reports; and

- representing the Secretary of Energy on the Interagency Task Force for implementation of Executive Order 12856.

\section{E.4 Assistant Secretary for Environmental Management (EM)}

In addition to his regular duties as head of a DOE line organization, the Assistant Secretary for EM is responsible for:

- providing overall leadership for the DOE-wide pollution prevention effort;

- providing the central point of coordination among CSOs and Operations Offices for implementing E.O. 12856;

- collecting, tracking, and compiling information on the progress of the Department's pollution prevention programs; and

- providing the necessary staff and resources to implement, manage, and maintain site crosscutting pollution prevention activities at each DOE site, as defined by this plan.

\section{E.5 Assistant Secrefary for Environment, Sufoly and Healih (EH)}

The Assistant Secretary for EH is responsible for:

- ensuring that policies and guidance facilitate compliance with pollution prevention statutes, regulations, and Executive Orders;

- developing DOE environmental compliance policies, guidance, requirements, and procedures for DOE operations and overseeing 
Departmental actions to comply with applicable pollution prevention laws and regulations;

- being the central point for environmental coordination among heads of Cognizant Secretarial Offices and field organizations and EPA;

- directing the DOE NEPA program;

- coordinating, preparing, and submitting pollution abatement plans and progress reports to EPA in accordance with E.O. 12088 and OMB Circular A-106;

- coordinating, preparing, and submitting the annual E.O 12856 progress report to EPA;

- providing oversight and compliance assessments of E.O. 12856 provisions at DOE sites; and

- evaluating and disseminating information that demonstrates the Department's compliance with E.O. 12856 requirements and results of the Department's efforts to implement pollution prevention measures to reduce the release and transfer of toxic chemicals.

\section{E.6 Headquarters Cognizant Secretarial Offices:}

The heads of DOE Cognizant Secretarial Offices are, for pollution prevention programs under their purview, responsible for:

- conserving resources and reducing the generation of waste and environmental releases;

- issuing policy, planning, and budget guidance that clearly establishes pollution prevention implementation as an element of their line programs;

- providing guidance in the development of sitespecific goals and budgets;

- providing the necessary staff and resources to develop and maintain generator-specific programs for all their sites, facilities, processes, and activities as defined in this plan;

- providing active leadership and program oversight for, and measurement and reporting of, pollution prevention activities;

- ensuring that actions are taken at their sites to comply with all requirements of E.O. 12856;

- conducting Research Development and Demonstration (RD\&D) critical needs assessments for technologies required to solve significant waste or emissions problems within their Cognizant Secretarial Offices, and for developing implementation plans for critical RD\&D projects;

- including pollution prevention principles in the designs of new facilities and projects; and

- ensuring public participation in the pollution prevention planning process.

\section{E.7 Pollution Prevention Executive Board}

The Executive Board provides leadership to achieve Secretarial goals and management objectives, develops and implements a Department-wide pollution prevention program as envisioned by the Pollution Prevention Program Plan, and develops and coordinates a DOE-wide program. The Executive Board also oversees the Department's external pollution prevention efforts directed toward assisting industry. The Executive Board is responsible for:

- establishing policies, priorities, and strategies for effective, coordinated pollution prevention programs;

- requesting the necessary staff and resources from each organization to complete Executive Board management objectives;

- setting priorities and providing guidance and direction to the WRSC; 
- monitoring progress on Secretarial objectives, key elements of the Pollution Prevention Program Plan and WRSC activities, and reporting to the Secretary on a regular basis to highlight progress; and

- resolving issues related to pollution prevention planning, budgeting, and execution referred to the Executive Board by Board members or the WRSC.

\section{E.8 Waste Reduction Steering Committee}

The WRSC is responsible for coordinating implementation of the Pollution Prevention Program Plan and assisting the Executive Board in carrying out its mission. The WRSC has additional responsibility to:

- oversee the development and coordination of pollution prevention crosscut planning and implementation of pollution prevention crosscutting activities as assigned by the Executive Board;

- work toward obtaining consistency in the conduct of pollution prevention efforts within each line organization;

- facilitate pollution prevention technical information exchange;

- assist in the development of Headquarters pollution prevention program guidance;

- review DOE-wide pollution prevention programs with the goal of enhancing resource efficiency and reducing duplication of effort;

- provide recommendations for additional pollution prevention initiatives to the Executive Board; and

- prepare reports on the status of pollution prevention programs, as necessary, for the Executive Board to relay to the Secretary.

\section{E.9 Office of the Associate Deputy Secretary for Field Management (FM)}

The Office of the Associate Deputy Secretary for FM is responsible for:

- participating in meetings and activities of the Pollution Prevention Executive Board and the WSRC;

- advocating Operations Office positions, funding, and staffing needs for pollution prevention;

- promoting Operations Office commitment to pollution prevention; and

- facilitating consolidated issue resolution among Operations Offices and Headquarters organizations.

\section{E.10 Operations Office Managers}

Managers of DOE Operations Offices are responsible for:

- implementing pollution prevention policies established by the Department, this Program Plan, and line program managers through issuance of site-specific guidance;

- reviewing site-specific, qualitative and quantitative pollution prevention goals for CSO approval;

- measuring site progress in implementing the DOE Program Plan's 18 activities by FY 2000 , and taking corrective actions, as necessary;

- supporting adequate resources for pollution prevention activities through planning, budgeting, and cost/benefit reviews;

- integrating the various requirements for site coordination, generator pollution prevention activity implementation, waste operations pollution prevention activity implementation, and technology development into a comprehensive program; 
- ensuring that pollution prevention activities are consistent with regulatory requirements and agreements;

- integrating pollution prevention guidelines into other site operational activities such as safety, health, design, and procurement;

- integrating pollution prevention guidelines into contractual agreements and employee performance evaluations, as required;

- validating measurement and reporting procedures;

- ensuring that program reporting is timely and consistent with other data reports; and

- reviewing site pollution prevention plans for CSO approval.

\section{E.11 Heads of Contractor Organizations}

Heads of contractor organizations are responsible for carrying out the work that has been assigned to them by Heads of Departmental Elements as stated in their contracts. In the area of pollution prevention, contractor organizations may be directed to carry out the following types of activities:

- achieving site-specific goals for reducing waste generation and environmental releases;

- establishing an aggressive site pollution prevention program to implement the DOE Pollution Prevention Program Plan's 18 activities by FY 2000 and demonstrating proactive leadership in implementing that program; ·

- conserving resources, reducing waste generation and environmental releases, and increasing recycling activities within their operations;

- ensure that pollution prevention requirements are included in procurement requests for contractor work to be performed on site at DOE-owned or -leased facilities;
- complying with DOE's affirmative procurement program and submitting the required annual reports;

- developing a contractor-specific pollution prevention plan consistent with guidance from $D O E$ Headquarters and their DOE Operations Office Managers;

- dedicating sufficient funding and resources to ensure implementation of, and reporting on, source reduction measures and recycling activities identified in their pollution prevention plans;

- reporting on implementation of source reduction measures, recycling efforts, and the effects on waste generation and environmental release rates;

- certifying the accuracy of reports prepared for DOE; and

- ensuring public participation in the pollution prevention planning process. 